\title{
Arctic Ocean Circulation Patterns Revealed by GRACE
}

\author{
Cecilia Peralta-Ferriz and James H. Morison \\ Polar Science Center, Applied Physics Laboratory, University of Washington, Seattle, Washington \\ JOHN M. WALLACE \\ Department of Atmospheric Sciences, University of Washington, Seattle, Washington \\ JENNIFER A. BONIN \\ College of Marine Science, University of South Florida, Tampa, Florida \\ JINLUN ZHANG \\ Polar Science Center, Applied Physics Laboratory, University of Washington, Seattle, Washington
}

(Manuscript received 19 December 2012, in final form 15 October 2013)

\begin{abstract}
Measurements of ocean bottom pressure (OBP) anomalies from the satellite mission Gravity Recovery and Climate Experiment (GRACE), complemented by information from two ocean models, are used to investigate the variations and distribution of the Arctic Ocean mass from 2002 through 2011. The forcing and dynamics associated with the observed OBP changes are explored. Major findings are the identification of three primary temporal-spatial modes of OBP variability at monthly-to-interannual time scales with the following characteristics. Mode 1 (50\% of the variance) is a wintertime basin-coherent Arctic mass change forced by southerly winds through Fram Strait, and to a lesser extent through Bering Strait. These winds generate northward geostrophic current anomalies that increase the mass in the Arctic Ocean. Mode $2(20 \%)$ reveals a mass change along the Siberian shelves, driven by surface Ekman transport and associated with the Arctic Oscillation. Mode 3 (10\%) reveals a mass dipole, with mass decreasing in the Chukchi, East Siberian, and Laptev Seas, and mass increasing in the Barents and Kara Seas. During the summer, the mass decrease on the East Siberian shelves is due to the basin-scale anticyclonic atmospheric circulation that removes mass from the shelves via Ekman transport. During the winter, the forcing mechanisms include a large-scale cyclonic atmospheric circulation in the eastern-central Arctic that produces mass divergence into the Canada Basin and the Barents Sea. In addition, strengthening of the Beaufort high tends to remove mass from the East Siberian and Chukchi Seas. Supporting previous modeling results, the month-to-month variability in OBP associated with each mode is predominantly of barotropic character.
\end{abstract}

\section{Introduction}

Arctic change has been reflected in decreasing sea ice thickness (Kwok and Rothrock 2009), reduced summer sea ice extent (Stroeve et al. 2007, 2008; Comiso 2012), changed freshwater content and distribution (McPhee et al. 2009; Rabe et al. 2011; Morison et al. 2012; Giles et al. 2012), and increased atmospheric temperature

Corresponding author address: Cecilia Peralta-Ferriz, Polar Science Center, Applied Physics Laboratory, University of Washington, 1013 NE 40th St., Seattle, WA 98105.

E-mail: ferriz@apl.washington.edu
(Overland et al. 2008) and oceanic heat content (Steele et al. 2008; Polyakov et al. 2010). Changes in all these properties are of concern given their possible linkages with global climate, for example by controlling stratification in the sub-Arctic seas and thereby modulating convection and the meridional overturning circulation (Aagaard and Carmack 1989; Hu et al. 2010).

These changes have been linked to the Arctic Ocean circulation and climate variability (Morison et al. 2000, 2006). During the late 1980s and early 1990s, the leading mode of hemispheric surface atmospheric pressure, the Arctic Oscillation (AO; Thompson and Wallace 1998), entered an extreme positive phase. Positive AO is 
expressed as low surface atmospheric pressure over the Arctic Ocean. During these years of positive AO, the extent of the anticyclonic Beaufort high decreased, leading to a counterclockwise shift of the transpolar drift or zero vorticity line of sea ice motion (Rigor et al. 2002) accompanied by a counterclockwise shift of the frontal line between Pacific- and Atlantic-derived waters in the central basin (Steele et al. 2004). This shift was consistent with a salinity increase in the upper ocean of the central Arctic (Morison et al. 2000). The cold halocline also weakened and retreated counterclockwise (Steele and Boyd 1998), enhancing melting of sea ice through the increased ice exposure to warm Atlantic water. As the atmospheric circulation directly affects sea ice motion, the wind field associated with the positive AO increased the export of multiyear ice through Fram Strait (Rigor et al. 2002; Rigor and Wallace 2004).

During the early 2000s, the Arctic circulation relaxed toward pre-1990s climatological conditions, including a near-zero upper ocean salinity anomaly at the North Pole (Morison et al. 2006). However, cyclonic high-AO conditions appeared again after a positive jump in the AO in 2007 (Morison et al. 2012).

To understand the rapid changes in the Arctic Ocean and their role in climate change, it is necessary to learn the basic patterns of circulation variation. Observations by the National Aeronautics and Space Administration (NASA) mission Gravity Recovery and Climate Experiment (GRACE) of the time-varying mass field provide a new approach to measure these patterns of change. Since March of 2002, GRACE has provided essentially full coverage of ocean bottom pressure (OBP) over the Arctic Ocean. In this study, a decade of GRACE and in situ OBP observations reveal the patterns of circulation change and the unveiled forcing mechanisms are investigated using output from two state-of-the-art ice-ocean models.

In what follows in section 2, the relevance of ocean bottom pressure as a tool to understand ocean circulation is presented, and background work on GRACE is introduced. Section 3 describes the datasets and section 4 includes validation of satellite and models with in situ observations. Section 5 shows the patterns of variability of the GRACE bottom pressure field, and their associated forcing. A summary and conclusions are presented in section 6 .

\section{Background}

The goal of GRACE is to measure the time-varying gravity field of Earth. Over the ocean, changes in the time-varying gravitational field reflect temporal variations of the OBP field. The conversion from gravitational field to OBP has been explained by Wahr et al.
(1998). Of particular interest to the polar research field is the orbit of the GRACE satellites (i.e., $89^{\circ}$ of inclination), which allows for essentially full coverage over the Arctic Ocean, and better temporal resolution for high-latitude regions, where mass distribution changes in the ocean, along with mass changes because of glacier melt and hence sea level rise, are of major concern to climate change.

OBP measurements can determine the abyssal flow characteristics using the geostrophic relation (Luther and Chave 1993). With simultaneous observations of OBP in different locations, the barotropic mass transport between the locations may be determined (Wearn and Baker 1980; Morison 1991). Ocean mass transport may be used to study overturning flow variations (Roussenov et al. 2008), mass exchange between ocean basins (Hughes and Stepanov 2004; Stepanov and Hughes 2006; Chambers and Willis 2009), and freshwater changes in the ocean (Morison et al. 2007, 2012). On a broader scale, changes in mass, and therefore changes in OBP, are directly related to water mass exchanges among the ocean, cryosphere, and hydrosphere (Wahr et al. 1998).

OBP is the sum of atmospheric and oceanic mass. Total ocean bottom pressure $P_{b}$ is the integral of the hydrostatic relation from the bottom of the ocean to the top (Ponte 1999):

$$
P_{b}=\rho_{o} g \eta+g \int_{-H}^{0} \rho d z+P_{a},
$$

where

$$
\eta=\eta^{\prime}+\frac{1}{\rho_{o} g}\left(\overline{P_{a}}-P_{a}\right) .
$$

In this relation, $g$ is the gravitational acceleration, $H$ is the total depth, $\rho$ is the depth-dependent density, and $\rho_{o}$ is a constant or reference ocean water density, typically taken as $1028 \mathrm{~kg} \mathrm{~m}^{-3}$. Also, $P_{a}$ is the local surface atmospheric pressure and $\overline{P_{a}}$ is the spatially averaged surface pressure over the global oceans; $\eta$ is the sea surface height ( $\mathrm{SSH}$ ), which includes the dynamic part of the sea surface height, $\eta^{\prime}$, relative to the geoid, and the direct effect of the local atmospheric pressure loading (inverted barometer response), with a spatially averaged sea level pressure contribution.

Substituting Eq. (2) in Eq. (1), and rearranging terms, the OBP anomalies $P_{b}^{\prime}$ relative to the temporal mean or unperturbed field, may be expressed as

$$
P_{b}^{\prime}=\rho_{o} g \eta^{\prime}+g \int_{-H}^{0} \rho^{\prime} d z+\overline{P_{a}^{\prime}} .
$$


The global-mean atmospheric pressure over the ocean, $\overline{P_{a}^{\prime}}$ in Eq. (3), is usually neglected in most modeling studies (Ponte 1999), mainly because it does not lead to ocean dynamics. It does, however, affect the global-mean OBP. Throughout this work, we will ignore the global-mean SLP contribution, unless noted otherwise (e.g., for consistency between model and observation comparisons). The first term on the right-hand side in Eq. (3) is the contribution to the bottom pressure change resulting from SSH variation. The second term represents the bottom pressure contribution resulting from the density variations of the water column. If two of these three terms are known, then a complete picture of the changes in the ocean circulation may be revealed. In this work, we will sometimes refer to the pressure resulting from the vertically integrated density term as the steric pressure $P_{\mathrm{st}}^{\prime}$. Following Gill and Niiler (1973), steric pressure is the opposite sign of the steric height anomaly,

$$
\eta_{\text {steric }}^{\prime}=-\frac{1}{\rho_{o}} \int_{-H}^{0} \rho^{\prime} d z=-\frac{P_{\mathrm{st}}^{\prime}}{\rho_{o} g},
$$

that results from the combination of the thermosteric expansion and the halosteric contraction of the water column. Because of the low coefficient of thermal expansion at low temperatures, the stratification of the Arctic Ocean water column is dominated by salinity rather than temperature: the thermosteric or temperatureinduced SSH change is much smaller than the halosteric or salinity-induced SSH change.

Throughout this work, OBP variation will be referred to in its normalized form $\left(P_{b}^{\prime} / \rho_{o} g\right)$, and the units will be provided in equivalent water thickness, such that $1 \mathrm{mbar}$ (or $1 \mathrm{hPa}$ ) unit pressure corresponds to about $1 \mathrm{~cm}$ equivalent water thickness.

Thus, following Eq. (3) and ignoring the atmospheric term $\overline{P_{a}^{\prime}}$, OBP has two contributions: the steric pressure anomaly and the SSH anomaly. When the OBP change is dominated by the SSH anomaly (e.g., $\mathrm{OBP}=\mathrm{SSH}$ ), the ocean circulation is barotropic. When the steric pressure becomes dominant, the relationship between OBP and SSH breaks down, and the character of the ocean circulation is baroclinic.

The dominance of the barotropic contribution over the baroclinic contribution to OBP variations depends on depth, latitude, time scale, and stratification (Gill and Niiler 1973; Vinogradova et al. 2007; Bingham and Hughes 2008). Modeling studies indicate that at high latitudes (Vinogradova et al. 2007) and at the Arctic Ocean in particular (Bingham and Hughes 2008), and at annual and shorter time scales, the circulation is predominantly barotropic, whereas at interannual and longer time scales, circulation adjusts baroclinically. Only in the shallow regions of the Arctic shelves (e.g., $<200 \mathrm{~m}$ ) do the SSH fluctuations in the model of Bingham and Hughes (2008) remain coherent with OBP fluctuations at longer than seasonal time scales.

Observations generally confirm the model results. Ice, Cloud, and Land Elevation Satellite (ICESat) dynamic ocean topography (DOT) $\eta^{\prime}$ agrees with dynamic heights relative to $500 \mathrm{dbar}$ from in situ hydrography (Kwok and Morison 2011), indicating the general dominance of baroclinic adjustment. Recent trends in ICESat DOT, GRACE OBP, and in situ hydrography indicate that at multiyear time scales OBP changes are mainly as a result of steric changes, and circulation is largely baroclinic (Morison et al. 2012). Conversely, GRACE and in situ observations of OBP suggest the seasonal variations (Peralta-Ferriz and Morison 2010) and submonthly variations (Peralta-Ferriz et al. 2011) in Arctic Ocean mass are spatially coherent and barotropic. Furthermore in a more recent study, Volkov et al. (2013) used GRACE and altimetry observations to quantify the sea level fluctuations in the Barents Sea at different time scales, and demonstrated that at intraseasonal time scales, the mass-related variability of sea level explains a large amount of the total sea level change (e.g., OBP dominated by SSH instead of steric pressure).

\section{Data}

\section{a. GRACE ocean bottom pressure}

In this work, we use GRACE release 4 data from August 2002 to August 2011 as provided by the University of Texas, Center for Space Research (CSR) and the Jet Propulsion Laboratory (JPL). (These data are available online at ftp://podaac-ftp.jpl.nasa.gov/allData/ tellus/L3/ocean_mass/.)

GRACE OBP observations have become a powerful tool for investigating ocean dynamics that have been otherwise limited to sporadic locations or done with only short-term observations. They have been validated by several studies. Rietbroek et al. (2006) compared GRACE OBP with pressure gauges in the CrozetKerguelen region of the southern Indian Ocean, and found significant correlation and that the signal-to-noise ratio between GRACE and the difference of GRACE minus in situ data was greater than one. Munekane (2007) compared three years of GRACE OBP with five in situ pressure sensors from the National Oceanic and Atmospheric Administration (NOAA)'s Deep-Ocean Assessment and Reporting of Tsunamis (DART) gauges in the northeast Pacific Ocean and found good 
correlations between the individual in situ data and the GRACE OBP at each location. The average OBP of the four most closely clustered pressure gauges showed an RMS difference from GRACE OBP of $1.8 \mathrm{~cm}$.

One study suggests that the signal-to-noise ratio of GRACE OBP is largest at high latitudes (Kanzow et al. 2005). Since most of the Arctic Ocean falls under the $600-\mathrm{km}$ footprint of GRACE more often than do lowerlatitude regions, the potential to recover high-frequency variations of OBP is greater, and more accurate monthly averages of OBP may be obtained. Morison et al. (2007) compared GRACE OBP at the North Pole to in situ OBP measurements from two Arctic bottom pressure recorders (ABPRs). The GRACE OBP and monthly averages corresponding to the GRACE monthly values agree to $2.6 \mathrm{~cm}$. The GRACE-ABPR agreement at the North Pole $(R=0.75)$ highlights the tendency of GRACE to generate more accurate measurements at high latitudes compared to lower latitudes (Morison et al. 2007; Kanzow et al. 2005). Monthly OBP observations from GRACE also show good agreement with in situ observations in the Beaufort Sea and Fram Strait (Peralta-Ferriz and Morison 2010).

For this study, data have been processed following Chambers $(2006 \mathrm{a}, \mathrm{b})$. The processing includes a correction for the postglacial rebound using the model of Paulson et al. (2007), and a destriping algorithm (Chambers 2006a) to remove the north-south propagating errors of the gravity coefficients described by Swenson and Wahr (2006). The data are also filtered with a 300- or 500-km-radius Gaussian, and a spherical harmonic filter cutoff at $40^{\circ}$. Monthly means of the Ocean Model for Circulation and Tides (OMCT) are added back to the GRACE solutions to obtain the OBP variations. A special algorithm is also applied to minimize the leakage from land signals onto ocean signals. There are four missing solutions out of the 109-month record used because of technical issues with the GRACE satellites. (More details on the GRACE satellite system may be found online at http://grace.jpl. nasa.gov/.)

While Chambers (2006b) applied a correction for the mass leakage from land into the ocean, strong signals remained in the Arctic Ocean, particularly near the regions of recent significant glacial mass loss (e.g., around Greenland). An alternative method for removing the land contamination of the ocean mass change by the mass loss signals of Greenland and Svalbard has been performed here (Bonin and Chambers 2013). This method consists of separating the landmass and ocean mass regions into several different basins, where each basin is assumed to have constant mass density. Sixteen basins are used across Greenland (eight in the coast, and eight in the interior), with 13 other land regions (including Iceland and Svalbard) and four ocean regions of semicoherent mass variation identified by the autocovariance of the OMCT time series. From the GRACE data, least squares estimation is used to solve for the mass signal in each basin predicted to create that signal. The "forward model" solution over the land basins is then smoothed with either a $300-$ or $500-\mathrm{km}$-radius Gaussian filter, to estimate the land leakage from those areas into the ocean. This leakage estimate is removed from the original GRACE solutions, producing a leakage-removed mass signal.

We considered two GRACE postprocessed solutions optimized in this way: 1) GRACE-300 was destriped (Chambers 2006a) and smoothed with a 300-km radius Gaussian filter, and 2) GRACE-500 was not destriped but was smoothed with a 500-km radius Gaussian filter (Fig. 1). The reasoning for considering a solution without destriping follows the hypothesis that the larger filter $(500 \mathrm{~km})$ may potentially eliminate the stripes without introducing any artifacts resulting from the nonlinear destriping algorithm (Bonin and Chambers 2013). Comparison of trends from 2002 to 2009 of GRACE-300 solutions and previous available solutions [e.g., version dpc201012 by Chambers (2006b)] illustrate the effectiveness of the optimization scheme in removing terrestrial mass change signal leakage into the ocean domain, particularly around Greenland (Fig. 1). Away from the regions of leakage optimization, GRACE-300, GRACE-500, and the previously available solutions of GRACE remain consistent in structure.

Overall, the GRACE-300 correlations with the available in situ data (Table 1; data will be described in the next section) were found to be slightly better than the GRACE-500 correlations (Table 2), and the analysis performed on GRACE-500 yielded results nearly identical to the analysis performed on GRACE-300 (shown in sections to follow). Therefore, GRACE-300 with its better spatial resolution was selected to investigate the physical mechanisms associated with the modes of OBP variability.

\section{b. In situ pressure observations}

Figure 2 shows the location of pressure and tide gauges with data used in this work for validation of OBP from GRACE and model output. The location of each in situ record, length of the record, sampling frequency, record gaps, and institution responsible for the data are summarized in Table 1. All the tide and pressure gauge records were detided and averaged daily and monthly. All tide gauge data were corrected for the invertedbarometer (IB) effect to yield the dynamic portion of the SSH, using daily local sea level pressure (SLP) from 

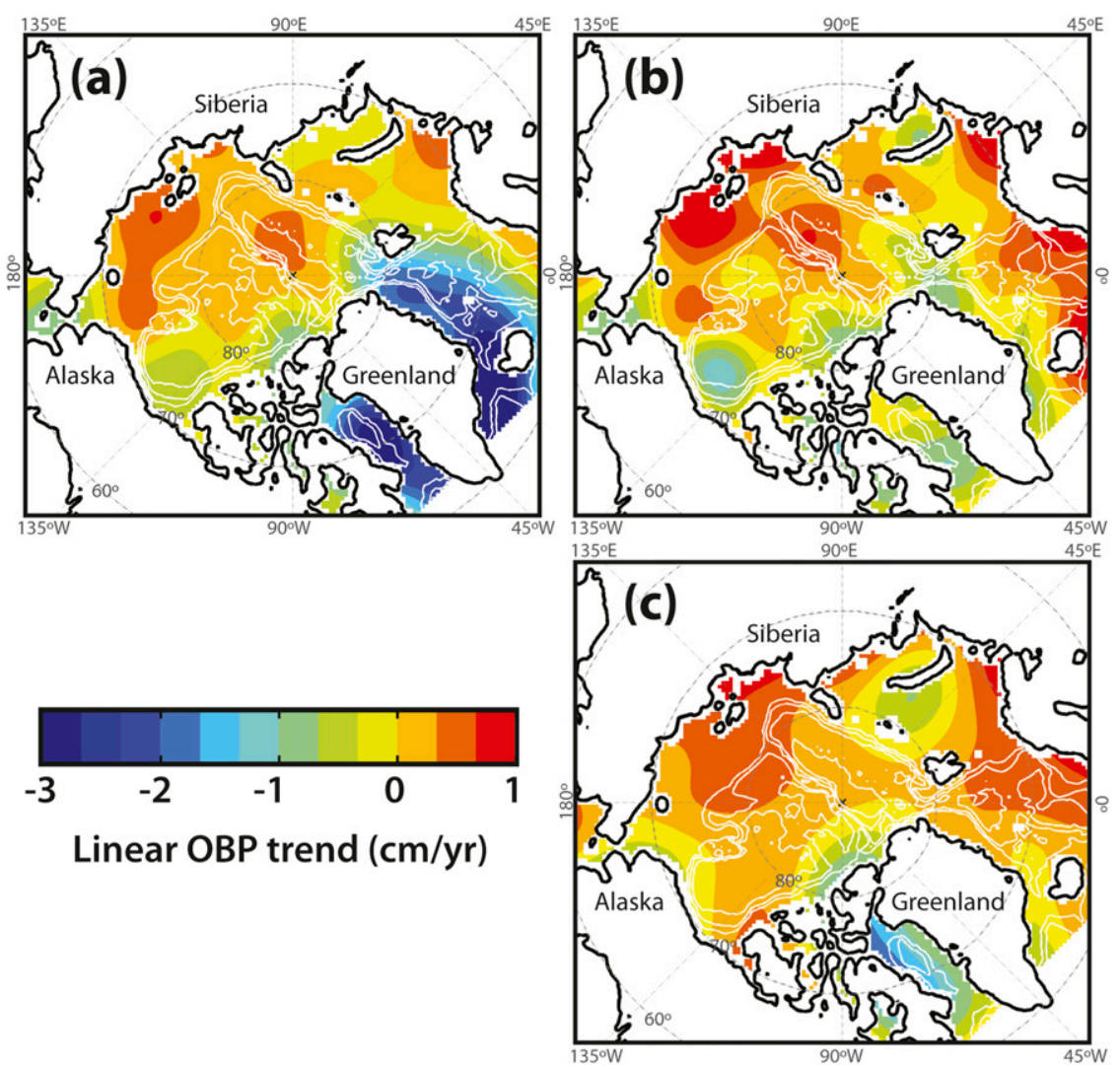

FIG. 1. OBP trend (August 2002-December 2009) using CSR GRACE release 4 data (a) destriped and smoothed with Gaussian filter of $300-\mathrm{km}$ radius, processed by Chambers (2006a); (b) destriped and smoothed with a 300-km-radius filter, and the optimized solution to reduce land contamination as explained in the text; and (c) as in (b), but non-destriped and using a 500-km-radius Gaussian filter. White contours show the International Bathymetric Chart of the Arctic Ocean (IBCAO), version 2.23, data from Jakobsson et al. (2008), at 1000-m intervals.

the National Centers for Environmental Prediction (NCEP)-National Center for Atmospheric Research (NCAR) reanalysis (Kalnay et al. 1996).

\section{c. Atmospheric data}

The atmospheric data used here consist of zonal and meridional wind velocity fields at $925 \mathrm{hPa}$, and surface atmospheric pressure from the NCEP-NCAR reanalysis (Kalnay et al. 1996). (The data are available online at http://www.esrl.noaa.gov/psd/.) Monthly averages from 2000 to 2011 are used. Monthly values of the Arctic Oscillation Index are obtained from the NOAA/NCEP, Climate Prediction Center (available online at http:// www.cpc.ncep.noaa.gov/products/precip/CWlink/daily_ ao_index/ao.shtml).

\section{d. Models}

We use monthly OBP and SSH output from two ocean models, the Pan-Arctic-Ice Ocean Modeling Assimilation System (PIOMAS) and Estimating the
Circulation and Climate of the Ocean, phase 2 (ECCO2; phase 2 covers high-resolution global-ocean and sea ice data synthesis).

PIOMAS is a regional ice-ocean model with 30 vertical levels and spatial resolution better than $22 \mathrm{~km}$ (Zhang and Rothrock 2003). The "North Pole" of the PIOMAS model is located in northern Greenland, with the goal of maximizing the resolution of flow exchange in the region of Fram Strait. PIOMAS is one-way nested to a global ocean model at $49^{\circ} \mathrm{N}$, and is forced by the winds and surface atmospheric pressure from NCEPNCAR reanalysis data (Kalnay et al. 1996). Monthly output of OBP and SSH anomalies are used from January 2000 to December 2009.

ECCO2 was developed by the NASA Modeling, Analysis, and Prediction (MAP) program. Synthesis data for ECCO2 are obtained from the global ocean and sea ice configuration of the Massachusetts Institute of Technology general circulation model (MITgcm), and the available in situ and satellite data. The optimized 
TABLE 1. Stations of in situ pressure and tide gauges, location, length of record, sampling frequency, monthly record gaps, and source or institution responsible.

\begin{tabular}{|c|c|c|c|c|c|c|}
\hline Station & Location & Gauge type & Temporal coverage & $\begin{array}{l}\text { Sampling } \\
\text { frequency }\end{array}$ & $\begin{array}{c}\text { Gaps } \\
\text { (month) }\end{array}$ & Program or institution \\
\hline North Pole & $89^{\circ} 15.26^{\prime} \mathrm{N}, 60^{\circ} 21.58^{\prime} \mathrm{E}$ & Pressure & Apr 2005-Apr 2011 & $15 \mathrm{~min}$ & - & $\begin{array}{l}\text { North Pole Environmental } \\
\text { Observatory (NPEO)/University } \\
\text { of Washington (UW) }\end{array}$ \\
\hline $\begin{array}{l}\text { Beaufort } \\
\text { Sea }\end{array}$ & $76^{\circ} 59.23^{\prime} \mathrm{N}, 139^{\circ} 54.5^{\prime} \mathrm{W}$ & Pressure & Aug 2003-Aug 2008 & $20 \mathrm{~min}$ & - & $\begin{array}{l}\text { Beaufort Gyre Exploration Project } \\
\text { (BGEP)/Woods Hole } \\
\text { Oceanographic Institution (WHOI) }\end{array}$ \\
\hline Fram Strait & $78^{\circ} 49.93^{\prime} \mathrm{N}, 5^{\circ} 0.87^{\prime} \mathrm{E}$ & Pressure & Oct 2003-Dec 2010 & $20 \mathrm{~min}$ & 1 & $\begin{array}{l}\text { Alfred Wegener Institute (AWI) for } \\
\text { Polar and Marine Research }\end{array}$ \\
\hline Bering Strait & $65^{\circ} 48.07^{\prime} \mathrm{N}, 168^{\circ} 47.9^{\prime} \mathrm{W}$ & Pressure & Sep 2007-Sep 2009 & $20 \mathrm{~min}$ & - & $\begin{array}{l}\text { Russian-American Long-Term } \\
\text { Census of the Arctic } \\
\text { (RUSALCA) }\end{array}$ \\
\hline Vardo & $70^{\circ} 19.8^{\prime} \mathrm{N}, 31^{\circ} 6^{\prime} \mathrm{E}$ & Tide & Aug 2002-Dec 2009 & Monthly & - & $\begin{array}{l}\text { Arctic and Antarctic Research } \\
\text { Institute (AARI)/Permanent } \\
\text { Service for Mean Sea } \\
\text { Level (PSMSL) }\end{array}$ \\
\hline Dunai & $73^{\circ} 55.8^{\prime} \mathrm{N}, 124^{\circ} 30^{\prime} \mathrm{E}$ & Tide & Aug 2002-Dec 2009 & Monthly & 2 & AARI/PSMSL \\
\hline Amderma & $69^{\circ} 45^{\prime} \mathrm{N}, 61^{\circ} 42^{\prime} \mathrm{E}$ & Tide & Aug 2002-Dec 2009 & Monthly & 1 & AARI/PSMSL \\
\hline UST & $69^{\circ} 15^{\prime} \mathrm{N}, 64^{\circ} 31.2^{\prime} \mathrm{E}$ & Tide & Aug 2002-Jan 2009 & Monthly & 11 & AARI/PSMSL \\
\hline Golomianyi & $79^{\circ} 33^{\prime} \mathrm{N}, 90^{\circ} 37.2^{\prime} \mathrm{E}$ & Tide & Aug 2002-Jul 2009 & Monthly & 9 & AARI/PSMSL \\
\hline Kigiliah & $73^{\circ} 19.8^{\prime} \mathrm{N}, 139^{\circ} 52.2^{\prime} \mathrm{E}$ & Tide & Aug 2002-Dec 2009 & Monthly & 1 & AARI/PSMSL \\
\hline Kotelnyi & $76^{\circ} \mathrm{N}, 137^{\circ} 52.2^{\prime} \mathrm{E}$ & Tide & Aug 2002-Dec 2009 & Monthly & 1 & AARI/PSMSL \\
\hline Pevek & $69^{\circ} 42^{\prime} \mathrm{N}, 170^{\circ} 15^{\prime} \mathrm{E}$ & Tide & Aug 2002-Dec 2009 & Monthly & 1 & AARI/PSMSL \\
\hline Sannikova & $74^{\circ} 39.6^{\prime} \mathrm{N}, 138^{\circ} 54^{\prime} \mathrm{E}$ & Tide & Sep 2002-Nov 2009 & Monthly & 3 & AARI/PSMSL \\
\hline Tiksi & $71^{\circ} 34.8^{\prime} \mathrm{N}, 128^{\circ} 54^{\prime} \mathrm{E}$ & Tide & Aug 2002-Dec 2009 & Monthly & - & AARI/PSMSL \\
\hline Tuktoyaktuk & $69^{\circ} 25.81^{\prime} \mathrm{N}, 132^{\circ} 59.4^{\prime} \mathrm{W}$ & Tide & Sep 2003-Dec 2009 & Hourly & 10 & $\begin{array}{l}\text { Department of Fisheries and } \\
\text { Oceans (DFO), Canada }\end{array}$ \\
\hline Holman & $70^{\circ} 44.21^{\prime} \mathrm{N}, 117^{\circ} 45.53^{\prime} \mathrm{W}$ & Tide & Jan 2003-Apr 2008 & Hourly & 1 & DFO, Canada \\
\hline Alert & $82^{\circ} 29.51^{\prime} \mathrm{N}, 62^{\circ} 19^{\prime} \mathrm{W}$ & Tide & Jan 2003-Jul 2009 & Hourly & 3 & DFO, Canada \\
\hline
\end{tabular}

ECCO2 version (Nguyen et al. 2011) of the model used here is forced with the Japanese 25-yr Reanalysis (JRA$25)$ project. It has 50 vertical levels, and an average spatial horizontal resolution of $18 \mathrm{~km}$. Monthly output of OBP and SSH anomalies are obtained from 2000 to 2009 .

Both PIOMAS and ECCO2 use the Boussinesq approximation, and they have a true free surface height. The modeled SSH is not affected by sea ice because neither PIOMAS nor ECCO2 uses nonlinear freshwater fluxes, nor do they use real freshwater fluxes. Instead, they apply a correction to the salinity field (virtual salt flux adjustment) by decreasing the salinity at most of the river mouths. In PIOMAS, this adjustment is based on monthly climatological values of runoff input into the ocean using values of runoff discharge from Hibler and Bryan (1987). ECCO2 uses newer climatological values of monthly-mean estuarine fluxes of freshwater, which are based on the Regional, Electronic, Hydrographic Data Network for the Arctic Region (R-ArcticNET) dataset (Lammers et al. 2001). These values are further adjusted for underestimated freshwater fluxes by multiplying for a factor of 1.2 (Nguyen et al. 2011). This adjustment helps the freshwater budget of the model to be closer to other estimates (e.g., Serreze et al.2006). Finally, neither PIOMAS nor ECCO2 includes the global-mean SLP, which is a term included in GRACE OBP. ECCO2 includes the global-mean freshwater cycle (A. Nguyen 2013, personal communication) but PIOMAS does not (global-mean freshwater cycle equals global-mean OBP minus global-mean SLP). Although these global-mean contributions to OBP are small (RMS $\sim 0.5 \mathrm{~cm}$ ) and are strongly dominated by the seasonal cycle, they are taken into account when comparing the different products of $\mathrm{OBP}$ and $\mathrm{SSH}$, as explained in the following sections.

\section{Validation of GRACE and model OBP}

\section{a. GRACE-in situ comparison}

GRACE-300 is validated with the available in situ monthly averaged records from the stations shown in Fig. 2. To do so, we linearly interpolated GRACE data onto the locations of tide and pressure gauges. Before we compare GRACE with the IB-corrected records from tide gauges, we removed the global-mean SLP 
TABLE 2. Correlation coefficient $R$, RMS variability, and RMS difference between the monthly averaged tide or pressure gauge records in the Arctic Ocean and GRACE, and between the in situ records and the model (RMSE). The seasonal variation was removed from all the time series. For the model-observation correlations, the numbers in parentheses include the seasonal variation. All coefficients in boldface are significant above the 95\% confidence level. RMS and RMSE units are centimeters. Modeled OBP is validated with in situ OBP data from pressure sensors (first four locations), and modeled SSH is validated with in situ data from tide gauges. Station names labeled Kara Sea and Laptev Sea correspond to the averaged tide gauge data within the Kara (5-8) and Laptev (9-13) Seas, respectively. GRACE and modeled time series are also averaged there for consistency.

\begin{tabular}{|c|c|c|c|c|c|c|c|c|c|c|c|c|c|c|}
\hline \multirow[b]{2}{*}{ No. } & \multicolumn{2}{|l|}{ In situ data } & \multicolumn{3}{|c|}{ GRACE-300 } & \multicolumn{3}{|c|}{ GRACE-500 } & \multicolumn{3}{|c|}{ PIOMAS } & \multicolumn{3}{|c|}{$\mathrm{ECCO} 2$} \\
\hline & Station & RMS & $R$ & RMS & RMSE & $R$ & RMS & RMSE & $R$ & RMS & RMSE & $R$ & RMS & RMSE \\
\hline 1 & North Pole & 2.3 & 0.76 & 3.3 & 2.42 & 0.79 & 2.8 & 1.82 & $0.41(0.58)$ & 1.4 & 2.52 & $0.56(0.46)$ & 1.3 & 1.94 \\
\hline 2 & Fram Strait & 2.0 & 0.31 & 2.2 & 2.47 & 0.13 & 2.9 & 3.75 & $0.64(0.69)$ & 1.8 & 1.69 & $0.38(0.34)$ & 1.3 & 1.91 \\
\hline 3 & Beaufort Sea & 3.5 & 0.56 & 2.4 & 2.98 & 0.16 & 2.9 & 4.19 & $0.51(0.69)$ & 1.9 & 3.06 & 0.39 (0.49) & 1.8 & 3.27 \\
\hline 4 & Bering Strait & 4.4 & 0.48 & 3.8 & 4.58 & 0.55 & 3.2 & 4.13 & $0.43(0.77)$ & 7.6 & 7.56 & 0.32 (0.61) & 5.3 & 5.69 \\
\hline 5 & Vardo & 4.1 & 0.25 & 2.8 & 4.32 & 0.36 & 2.8 & 4.02 & $0.72(0.76)$ & 2.7 & 2.83 & $0.51(0.82)$ & 3.7 & 3.88 \\
\hline 6 & Amderma & 6.6 & $\mathbf{0 . 3 3}$ & 2.7 & 6.31 & 0.47 & 2.7 & 5.89 & $0.44(0.66)$ & 3.9 & 6.04 & $0.73(0.83)$ & 3.8 & 4.70 \\
\hline 7 & UST & 7.4 & 0.32 & 2.3 & 7.09 & 0.47 & 3. & 6.63 & $0.26(\mathbf{0 . 4 8})$ & 4.4 & 7.63 & $0.46(0.60)$ & 4.5 & 6.69 \\
\hline \multirow[t]{2}{*}{8} & Golomianyi & 4.7 & 0.07 & 2.3 & 5.13 & 0.31 & 1. & 4.54 & $0.53(0.64)$ & 3.8 & 4.24 & $0.59(0.69)$ & 2.4 & 3.85 \\
\hline & Kara Sea $(5-8)$ & 5.8 & 0.43 & 2.2 & 5.28 & 0.55 & 2.2 & 4.44 & $0.56(0.76)$ & 3.4 & 4.81 & $0.81(0.86)$ & 3.6 & 3.5 \\
\hline 9 & Dunai & 13.1 & 0.40 & 3.9 & 12.1 & 0.23 & 3.1 & 12.7 & $0.38(0.54)$ & 5.1 & 12.1 & 0.29 (0.42) & 4.4 & 12.5 \\
\hline 10 & Tiksi & 12.9 & 0.22 & 3.7 & 12.6 & 0.29 & 3.1 & 12.3 & & & 12.1 & & 5.8 & 12.1 \\
\hline 11 & Kigiliah & 8.1 & 0.49 & 3.8 & 7.16 & 0.47 & 3.4 & 7.23 & $0.61(0.71)$ & 6.4 & 6.64 & $0.67(0.74)$ & 5.2 & 6.03 \\
\hline 12 & Kotelnyi & 7.8 & 0.45 & 2.9 & 6.97 & 0.41 & 3.1 & 7.12 & $0.29(\mathbf{0 . 4 8})$ & 4.6 & 7.79 & $0.30(\mathbf{0 . 5 6 )}$ & 4.1 & 7.63 \\
\hline \multirow[t]{2}{*}{13} & Sannikova & 12.0 & 0.38 & 3.6 & 11.2 & 0.37 & 3.0 & & $0.22(\mathbf{0 . 4 0 )}$ & 4.5 & 11.8 & $0.28(0.38)$ & 3.6 & 11.6 \\
\hline & Laptev Sea (9-13) & 6.9 & 0.61 & 3.5 & 5.5 & 0.54 & 3.2 & 5.83 & $0.58(0.71)$ & 4.9 & 5.67 & $0.59(0.63)$ & 4.0 & 5.5 \\
\hline 14 & Pevek & 10.2 & 0.50 & 3.0 & 9.1 & 0.45 & 3.5 & 9.17 & $0.57(0.66)$ & 9.3 & 9.03 & $0.68(0.66)$ & 6.5 & 7.46 \\
\hline 15 & Tuktoyaktuk & 12.3 & 0.52 & 2.3 & 11.3 & 0.46 & 2.0 & 11.5 & $0.74(0.66)$ & 7.6 & 8.51 & $0.86(0.73)$ & 5.3 & 8.23 \\
\hline 16 & Holman & 4.6 & 0.48 & 2.2 & 4.08 & 0.18 & 2.9 & 4.99 & $0.82(0.91)$ & 4.0 & 2.73 & $0.71(0.87)$ & 2.9 & 3.30 \\
\hline 17 & Alert & 2.9 & 0.27 & 3.0 & 3.57 & 0.28 & 2.9 & 3.51 & 0.33 (0.60) & 2.2 & 2.96 & $0.56(0.53)$ & 2.5 & 2.57 \\
\hline
\end{tabular}

from GRACE for consistency with the tide gauges. Figure 3 shows the time series comparisons between GRACE OBP and in situ records for five locations: the North Pole, Fram Strait, averaged tide gauge records in the Kara Sea, averaged tide gauge records in the Laptev Sea, and the Canadian Arctic at Alert Station (Fig. 3). We averaged the records from the tide gauges located in the Laptev and Kara Seas (see map in Fig. 2) to remove the effects of localized processes of SSH change in the coast and around islands. This averaging offers a more realistic comparison with GRACE data, which have undergone several smoothing steps and have a large footprint (300- $\mathrm{km}$ radius).

The correlation between OBP from GRACE and the in situ data is good, particularly with the in situ records at the North Pole $(R=0.76)$, Fram Strait $(R=0.53)$, and

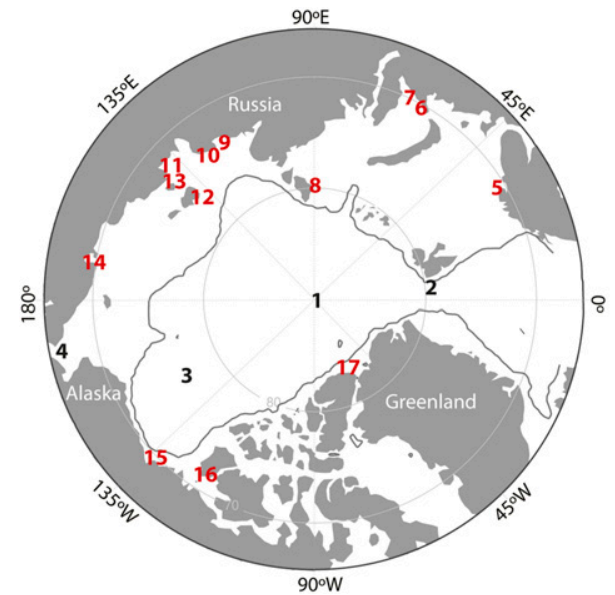

Pressure and tide gauges:

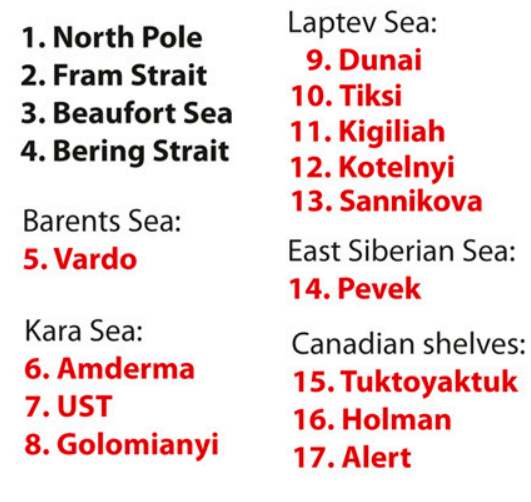

FIG. 2. Map of the Arctic Ocean with the location of in situ tide (red) and pressure (black) gauges used in this work. The gray solid line is the 500-m isobath from IBCAO (Jakobsson et al. 2008). The source of each of the records and more information on the datasets are shown in Table 1. 
(a) GRACE - in situ comparison

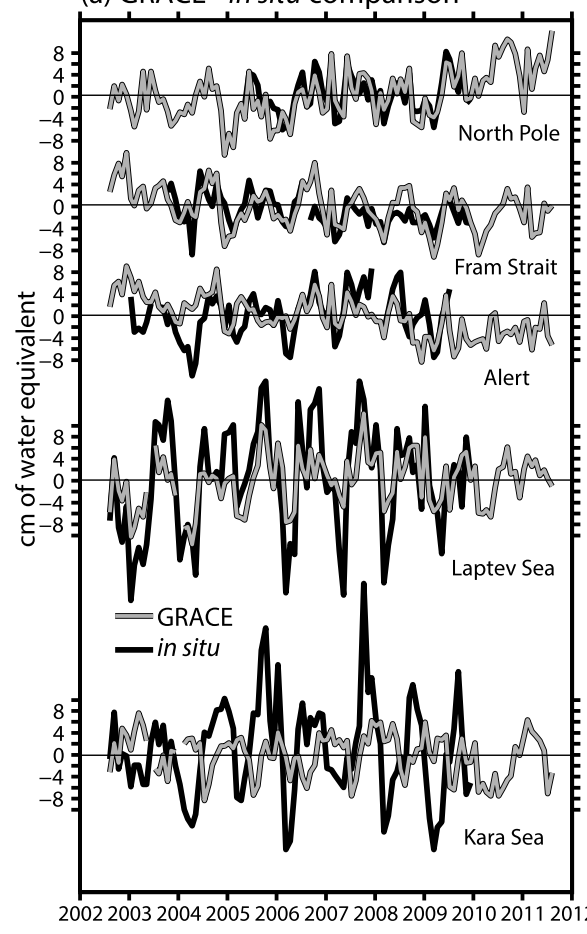

(b) Models - in situ comparison

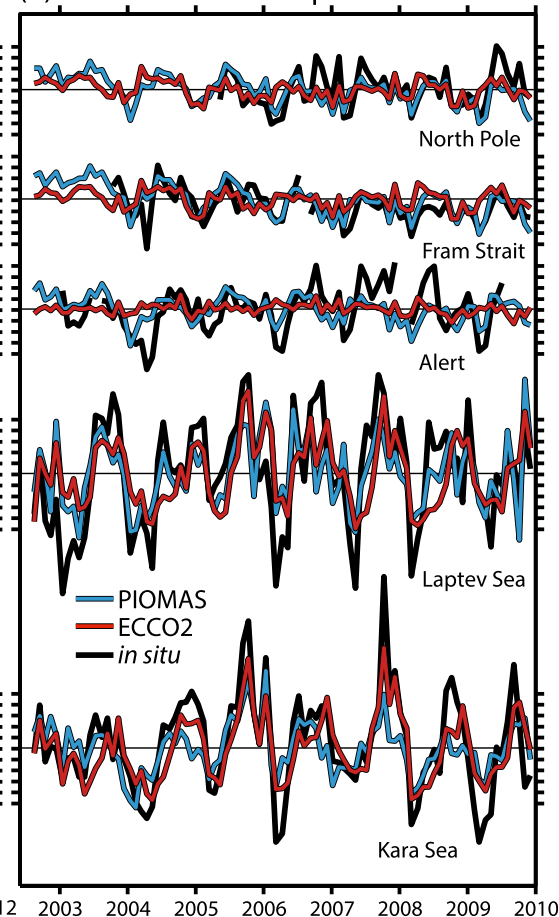

FIG. 3. (a) Monthly averaged time series of in situ (black) and GRACE (gray) OBP for five locations in the Arctic Ocean. (b) Monthly averaged time series of in situ, PIOMAS (blue), and ECCO2 (red) OBP or SSH at different locations. All the time series in the panels include the seasonal variation. Pressure and tide gauge locations are shown in Fig. 2.

averaged records in the Laptev Sea $(R=0.79)$. There is no correlation between GRACE OBP and the averaged record of tide gauges in the Kara Sea $(R=-0.04)$. The agreement improves in the Kara Sea when the seasonal variation of both GRACE and in situ records are removed (Fig. 4; $R=0.46$ ). The correlation coefficients $R$, RMS variability, and RMS differences between the in situ data and GRACE are shown in Table 2.

The highest correlation between GRACE-300 and in situ data with the seasonal variation removed (Fig. 4) is at the North Pole $(R=0.7)$, followed by the correlation with the averaged time series representative of the Laptev Sea $(R=0.61)$, and the correlation with the OBP records in the Beaufort Sea $(R=0.56)$ (Table 2). Generally, GRACE OBP is better correlated and has lower RMSE variability with in situ records in the open ocean regions (OBP-to-OBP comparison) than in the coastal regions, where most comparisons are rather between OBP and SSH from tide gauges (Table 2). In shallow regions the SSH variability is mostly barotropic, and therefore the difference between GRACE OBP and SSH would be expected to be small, perhaps resulting from some small steric influence. There could also be some leakage of the land signal into the ocean solutions of GRACE. This is a common problem for the ocean observations from GRACE (e.g., Fig. 1), which overall tends to make GRACE data less satisfactory in coastal regions relative to open ocean.

The discrepancy between GRACE and the in situ measurements in the Kara and Barents Seas (Vardo Station) when the seasonal variation is included may result from the mass changes on land leaking into the GRACE ocean signal as well. Although the GRACE solutions used here were optimized to reduce leakage from major glacial melt regions (i.e., Greenland, Iceland, and Svalbard), the amplitude of the hydrologic signals from the terrestrial Arctic watersheds $(\mathrm{Ob}$, Yenisey, Pechora, etc.) are also larger than the ocean gravity change, and thus may leak into the oceanic signals measured by GRACE. Supporting evidence of mass signal leakage from the Siberian Arctic watersheds is that the correlation between in situ data and GRACEOBP data in the Kara and Barents Seas is lower when the seasonal variation is included $(R=-0.04$ and 0.04 , respectively) than when it is removed $(R=0.46$ and 0.25 , respectively; see Table 2).

To get a hint of this, GRACE water storage [in centimeters of water thickness from Landerer and Swenson (2012), version ssv201008; August 2002-February 2012, available online at http://grace.jpl.nasa.gov] averaged 
(a) GRACE - in situ comparison

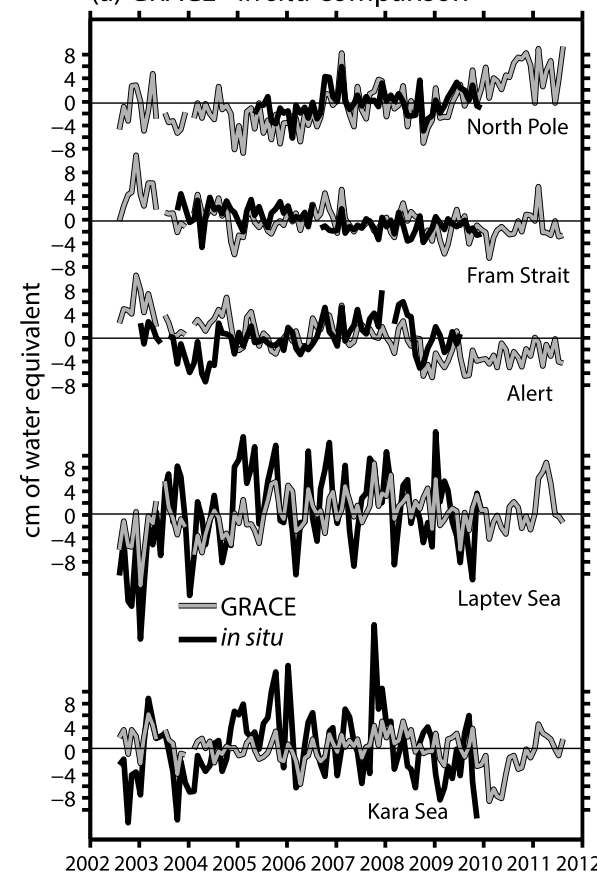

(b) Models - in situ comparison

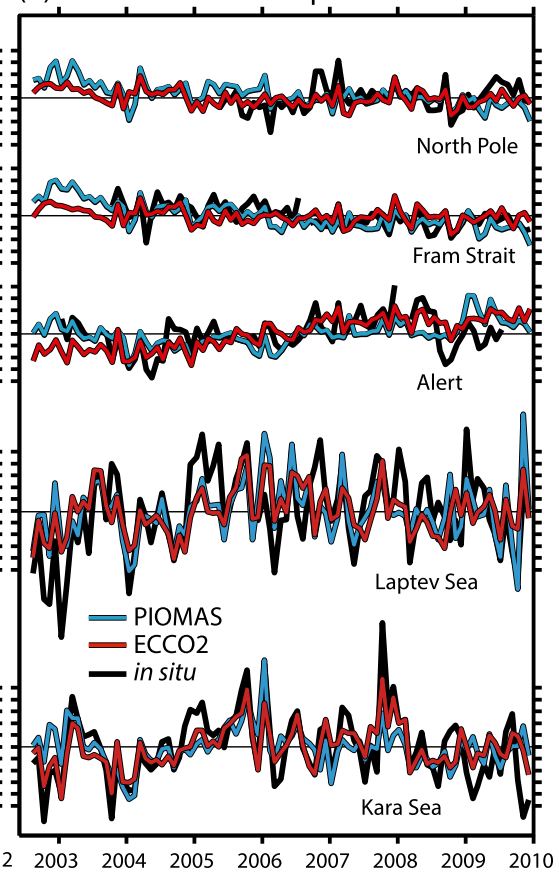

FIG. 4. As in Fig. 3, but all the time series in the panels have the seasonal variation removed.

over the watershed that discharges into the Kara Sea, and over the watershed of the Barents Sea (down to $60^{\circ} \mathrm{N}$ ), are compared with the GRACE ocean mass change averaged over the Kara Sea and the Barents Sea, respectively, in Fig. 5. There is significant correlation at zero lag between GRACE-derived OBP averaged over the Kara and Barents Seas and the GRACE-derived terrestrial water storage of the watershed that corresponds to each of these seas (Fig. 5). This suggests that at least part of the oceanic signal from GRACE may be due to leakage of land-based signal into the ocean solutions. On the other hand, there may be a component of the seasonal variation of Arctic OBP resulting from a spatially varying mass redistribution in the ocean that may produce a mass signal in the Kara and Barents Seas of the same phase as the land signal resulting from forcing unrelated to land processes (e.g., wind forcing; Peralta-Ferriz and Morison 2010).

In this work, the spatial and temporal variations of GRACE OBP are investigated at monthly-tointerannual time scales by excluding the seasonal variation explored by Peralta-Ferriz and Morison (2010), unless noted otherwise. The mean seasonal variation computed by the average of the available monthly means (means of January, February, March, etc.) from August 2002 to August 2011 has been removed from the monthly GRACE OBP. The seasonal variation of GRACE is similar to the seasonal variation of GRACE release 4 , using the $300-\mathrm{km}$ filtered data shown in Peralta-Ferriz and Morison (2010). The correlation coefficients and RMSE between GRACE and in situ data indicate that when the seasonal variation is removed, some of the correlation coefficients improve and rise above the significance level (Table 2).

\section{b. Models-in situ comparison}

The monthly averaged time series of modeled OBP and SSH from PIOMAS and ECCO2 are also compared with the monthly averaged in situ records from the pressure and tide gauges (Table 2; Figs. 3 and 4). For consistency, the model to observation comparisons included in Table 2 and Figs. 3 and 4 are between modeled OBP and OBP from pressure sensors, and between modeled SSH and SSH from the IB-corrected tide gauges. Also, prior to comparing model with in situ records, we add to the ECCO2-derived OBP the global-mean SLP, which is a term included in the pressure gauge records of OBP but missing in the $\mathrm{ECCO} 2$ model. We add to PIOMAS-derived OBP the full global-mean OBP (which is the sum of the global-mean SLP and the global-mean freshwater cycle). Finally, prior to comparing PIOMAS-derived SSH with SSH from tide gauges, we add to PIOMAS the global-mean freshwater cycle (global-mean OBP from GRACE minus global-mean SLP from NCEP), which is included in both $\mathrm{ECCO} 2$ and the tide-gauge SSH records. 

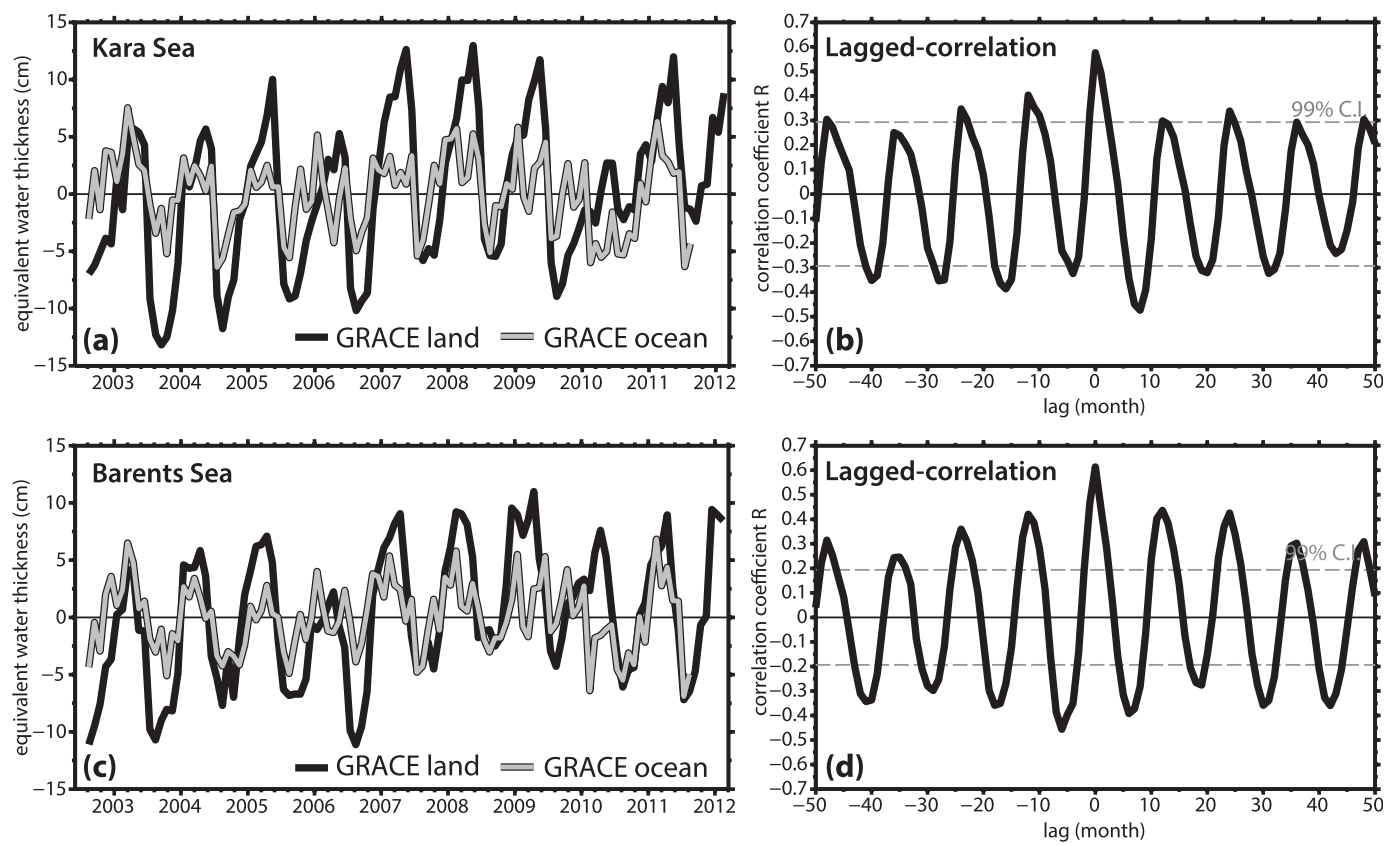

FIG. 5. (a) Time series of GRACE OBP averaged over the Kara Sea (gray) compared to GRACE time series of water storage on land averaged over the Kara watershed from the coast down to $60^{\circ} \mathrm{N}$ and from $60^{\circ}$ to $105^{\circ} \mathrm{E}$ (black). The error (measurement and leakage from adjacent regions) is estimated as $4.26 \mathrm{~cm}$ in that region, following Landerer and Swenson (2012). (b) Lagged correlation between GRACE-derived OBP and the GRACE landmass signal (black line). Dashed lines are the $99 \%$ confidence level. (c) As in (a), but for the Barents Sea, where the Barents watershed is delimited by the coast down to $60^{\circ} \mathrm{N}$ and from $15^{\circ}$ to $58^{\circ} \mathrm{E}$. The error for this region is estimated as $4.54 \mathrm{~cm}$. (d) As in (b), but for the Barents Sea watershed.

In Table 2, we include the correlation coefficients between the models and in situ data, with and without the seasonal variation. This is to show that there is excellent agreement between the in situ data and the models prior to altering the time series (e.g., by removing seasonal variation). After removing the seasonal variation from the time series, most of the correlation coefficients between the models and the data remain statistically significant (Table 2 ). The RMS variability of the OBP and SSH from the models are generally of the same order or slightly lower than the RMS of the in situ observations, and the RMS differences are similar or lower than the RMS of the in situ observations (Table 2).

\section{c. GRACE-model comparison}

Prior to comparing GRACE OBP with the modeled OBP, we smooth the modeled fields (OBP and SSH) with a $300-\mathrm{km}$ radius Gaussian filter, for consistency with the GRACE-300 processing. This smoothing decreases the RMS variability of the PIOMAS-derived fields approximately $20 \%-40 \%$, mainly near the coast of the Siberian shelves, particularly in the Chukchi and the East Siberian Seas, where the RMS amplitude of the modeled and observed OBP and SSH anomalies are the largest (Fig. 6). The effects of the Gaussian smoothing on the PIOMAS-derived SSH are also large along the southeastern coast of Greenland. The RMS difference between smoothed and nonsmoothed OBP and $\mathrm{SSH}$ from ECCO2 is slightly less than $1 \mathrm{~cm}$ over most of the Arctic Ocean. ECCO2 reproduces smaller RMS variability in the Chukchi and East Siberian Seas than PIOMAS does. Overall, larger effects of the smoothing filter occur in the regions of largest RMS mass variability (e.g., the East Siberian and Chukchi Seas). Thus, GRACE solutions are likely to underestimate by $20 \%-40 \%$ the OBP variations in situ in these shallow continental shelves, because of the smoothing filter applied to the satellite data.

An additional step prior to model-GRACE comparison consists of subtracting from the GRACE OBP the global-mean SLP averaged over the world oceans, because this term is not included in the models. ECCO2 does include the global-mean freshwater cycle. Therefore, for consistency among GRACE and the models, this term is also removed from GRACE and from ECCO2. These global-mean terms are dominated by the seasonal variation, for which, in addition to being small (relative to the local and regional variability in OBP), their effects on Arctic OBP variability are essentially suppressed when 
(a) PIOMAS - ECCO2

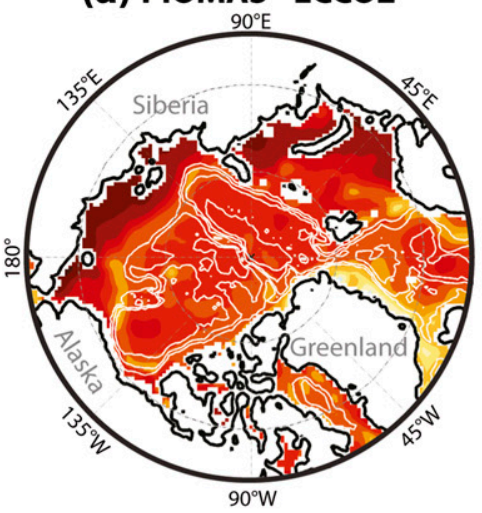

(d) GRACE

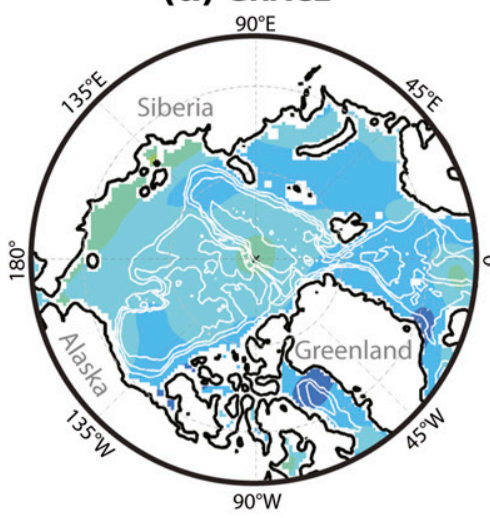

(g) PIOMAS - ECCO2

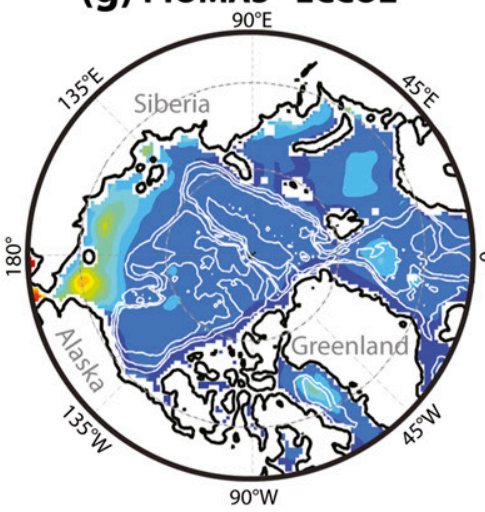

(b) GRACE - PIOMAS

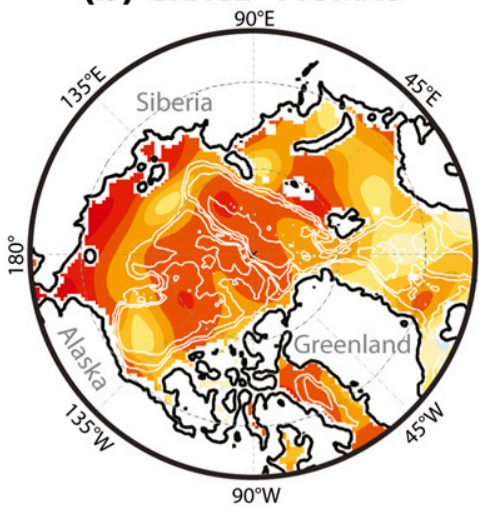

(e) PIOMAS

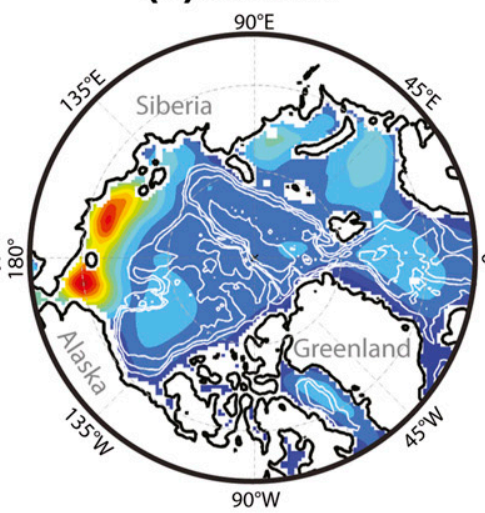

(h) GRACE - PIOMAS

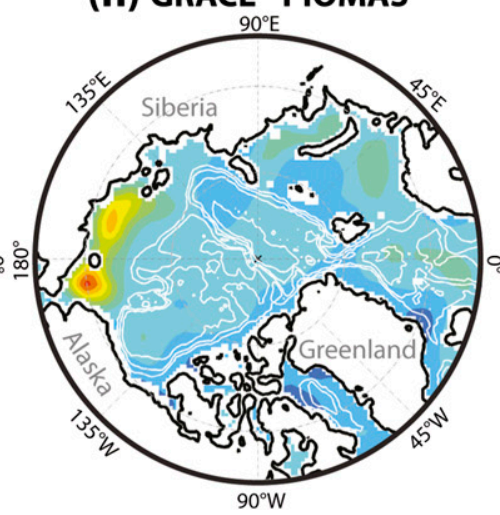

(c) GRACE - ECCO2

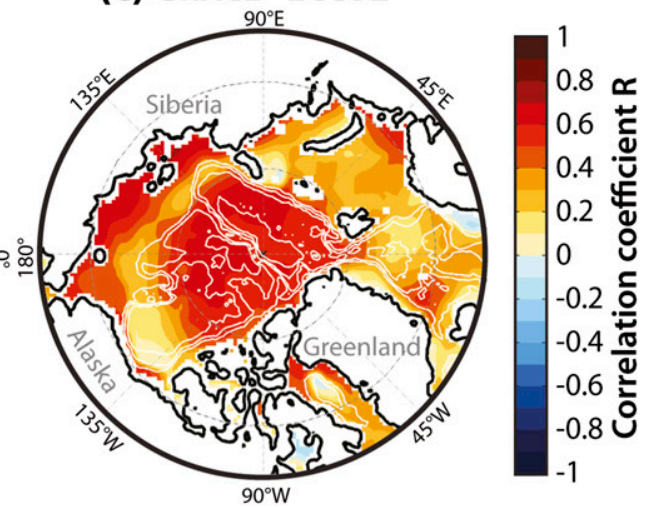

(f) ECCO2

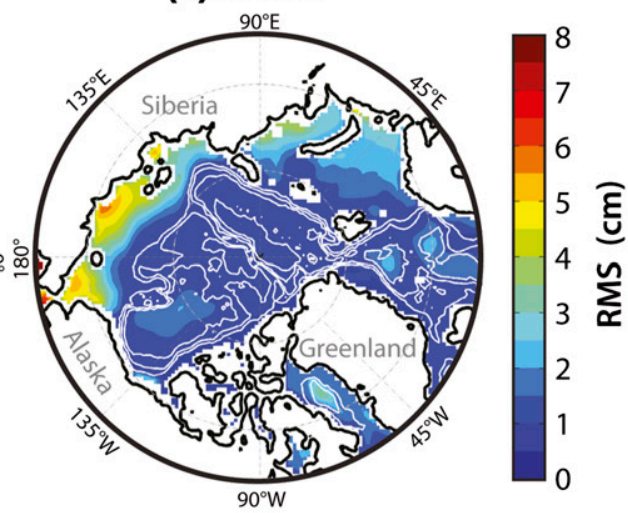

(i) GRACE - ECCO2

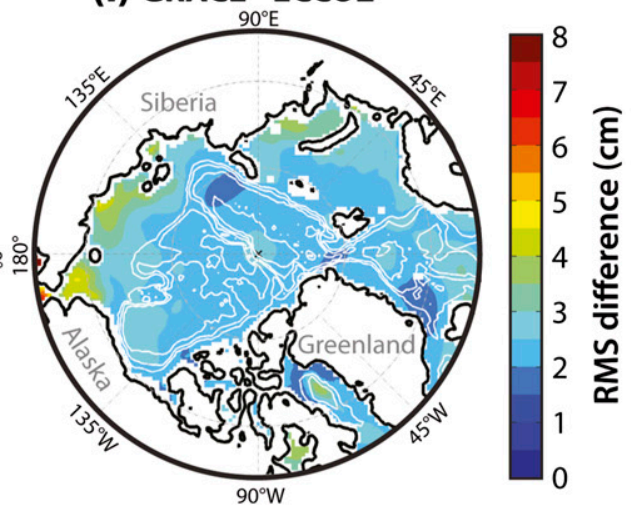

FIG. 6. Correlation coefficient of (a) PIOMAS with ECCO2-modeled OBP, (b) GRACE with equally smoothed PIOMAS OBP, and (c) GRACE with equally smoothed ECCO2 OBP. Correlations larger than 0.34 are significant above the $95 \%$ confidence level. RMS variability of OBP from (d) GRACE, (e) PIOMAS, and (f) ECCO2. RMS difference between (g) PIOMAS- and ECCO2-derived OBP, (h) GRACE and PIOMAS, and (i) GRACE and ECCO2. White contour lines are the IBCAO data (Jakobsson et al. 2008) at 1000-m intervals.

we remove the seasonal variation of all datasets. Thus, these terms are negligible in this work because we focus on the nonseasonal variability of the Arctic Ocean circulation and mass.

The comparisons of the $300-\mathrm{km}$ radius smoothed nonseasonal monthly OBP anomalies from PIOMAS and ECCO2 with GRACE show generally significant correlations (Fig. 6). The RMS difference between the models and GRACE is of the same order as the RMS variability of the individual fields. The RMS variability of the modeled OBP from both PIOMAS and ECCO2 are about one-third of GRACE OBP amplitude, particularly in the central basin. This results in larger RMS differences between GRACE and modeled OBP (Fig. 6). 
The model-to-model correlation is generally significant and above 0.5 , except along the Siberian shelf breaks. This low correlation at the shelf break may be associated with a problem the models have-widely known among the Arctic modeling community-in simulating effectively the advection of the Atlantic Water (e.g., Hunke et al. 2008). This problem may also affect the capability of the models to accurately represent the mass exchanges between the coastal regions and the deep basin, which could explain the larger RMS variability between GRACE and the modeled OBP in the central basin.

\section{Spatial and temporal variations of Arctic OBP}

We use empirical orthogonal function (EOF) analysis to identify the primary modes of variability of the GRACE OBP field. EOF analysis transforms a spacetime field into a set of vectors that are linear combinations of the original dataset. EOF decomposition is based on standard linear algebra techniques, singular value decomposition in this case. The set of vectors that results from the EOF decomposition is truncated to recover the leading modes, which explain most of the variance of the original dataset. EOF analysis of any space-time field yields three products for each mode: 1) a scalar that determines the relative dominance of the mode in terms of the amount of variance of the field explained by that mode, 2) a principal component (PC) time series, and 3) a spatial pattern that varies in amplitude and polarity, depending on the corresponding PC time series. Regression maps of the leading modes are obtained by projecting the original dataset onto the PC time series of each mode, and the units are the same as the original dataset per standard deviation (std) of the normalized PC time series.

EOF analysis was performed on the monthly record of GRACE-300 in the Arctic Ocean, from August 2002 to August 2011. The domain was delimited by the Bering Strait, Fram Strait, and the Barents Sea path from southern Svalbard to Norway along $15^{\circ} \mathrm{E}$. The Canadian archipelago channels were excluded. To focus on the month-to-month and interannual variations of Arctic OBP within a $10-y r$ period, the mean seasonal variation was removed. The 9-yr linear trend of the GRACE data (Fig. 1) was also removed prior to the EOF decomposition. The resulting modes of variability are anomalies relative to the overall mean field, longterm trend, and mean seasonal variability of the OBP field.

The EOF decomposition of the GRACE OBP reveals three significant modes (see Fig. 7, top), and these are well separated according to the criterion of North et al. (1982). The first mode explains $49 \%$ of the total variance and reveals a basin-coherent variation in mass. The second mode explains $19 \%$ of the variance and is characterized by a dipole of mass between the Siberian continental shelves and the central Arctic Ocean. The third mode explains $9 \%$ of the variance and shows a dipole of mass change between the Barents and Kara Seas and the East Siberian and Chukchi Seas (Fig. 7, bottom). The EOF decomposition of the PIOMAS- and ECCO2modeled OBP (not shown) reveals similar spatial patterns of variability as observed by GRACE. This shows further consistency between observations by GRACE and the models and provides confidence as to the capability of GRACE and the models to identify and extract meaningful physical processes through EOF analysis.

To recover the time variability corresponding to each of the three leading modes, we have projected the full dataset of GRACE (less the mean seasonal variation) onto the spatial pattern of each mode. The resulting time series for each of the modes are essentially the same as the principal component time series described above, except that the projection time series include the longterm trends associated with each mode. The projection time series of the leading modes, P1, P2, and P3, are shown in Fig. 8.

\section{a. Mode 1: A basinwide Arctic mass variation}

EOF1 reveals a basin-coherent mass change, with stronger center of action in the Central Basin (Fig. 7, upper left). The cross-correlation at zero lag of the time series P1 and the in situ OBP at the North Pole $[R=$ 0.67 , significant above $95 \%$ confidence interval $(\mathrm{CI})]$ is shown in Fig. 8. For consistency with GRACE-P1, the seasonal variation of the in situ OBP at the North Pole has also been removed. The cross-correlation supports our sense that GRACE is capturing real signals of mass change in the Arctic Ocean.

We can learn about the variations in seasonal behavior by examining the time series of P1 during cold months [December-April (DJFMA)] and warm months [June-September (JJAS)]. The regression maps of the GRACE OBP field in the Northern Hemisphere (north of $30^{\circ} \mathrm{N}$ ) projected upon the time series P1 (Fig. 9) shows that the OBP change associated with EOF1 is stronger during the winter months and much weaker during the summer months. Furthermore, while OBP increases in the Arctic during the winter, a slight drop of mass is observed in the North Atlantic and North Pacific (Fig. 9, left). The signals of decreasing mass at lower latitudes are of low amplitude but extend over an area wider than the Arctic Ocean.

The atmospheric forcing associated with the GRACE-OBP mode 1 is investigated by using monthly 

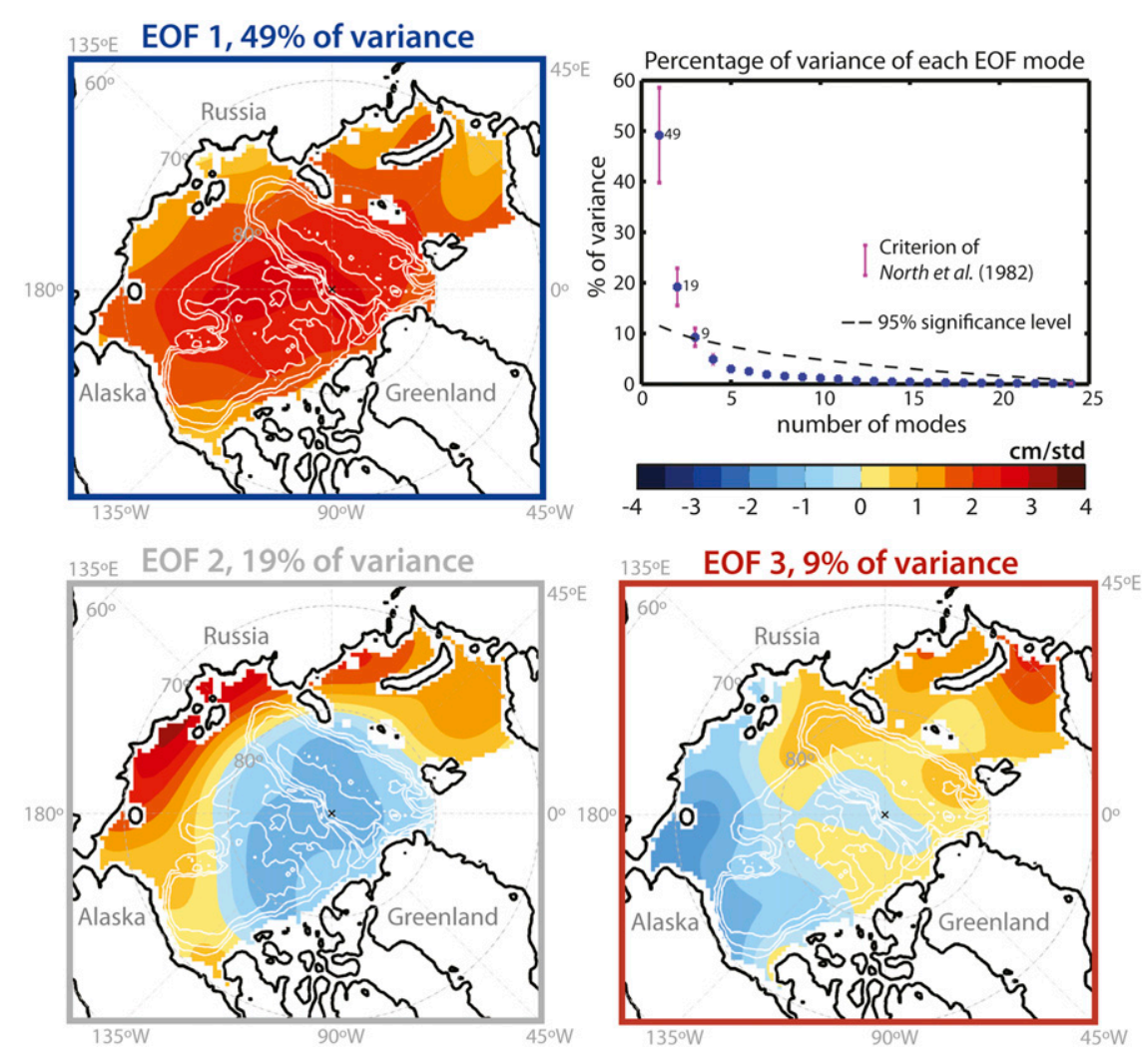

FIG. 7. (top right) Percentage of variance explained by the resulting EOF modes using singular value decomposition. Blue dots locate each mode. Pink bars are the confidence intervals for modal separation, estimated as in North et al. (1982). The black dashed line corresponds to the $95 \%$ level of confidence, estimated with a Monte Carlo simulation on random data. Regression maps of each of the EOF modes projected on their corresponding principal component time series for (top left) EOF1, (bottom left) EOF2, and (bottom right) EOF3. Units are in centimeters per standard deviation $\left(\mathrm{cm} \mathrm{std}^{-1}\right)$. White contour lines are the IBCAO data (Jakobsson et al. 2008) at 1000-m intervals.

NCEP-NCAR SLP and 925-hPa winds, north of $30^{\circ} \mathrm{N}$, from August 2002 to August 2011, with the mean seasonal variation removed. The SLP and wind fields were then regressed on the time series $\mathrm{P} 1$. The resulting regression maps (Fig. 10) suggest that the Arctic OBP change of this mode is not forced locally, and is strongly related to large-scale changes in atmospheric circulation over the North Atlantic and Nordic seas. The SLP pattern consists of a high-pressure anomaly over Scandinavia and a low-pressure anomaly over the North Atlantic centered at around $50^{\circ} \mathrm{N}$ (Fig. 10). The wind anomaly associated with P1 (Fig. 10, bottom) is consistent with the SLP pattern and shows predominantly southeasterly winds aligned from Scotland to Iceland and a strong northward component through the Nordic seas into the Arctic. Additional forcing into the Arctic basin is shown on the Pacific Ocean side, characterized by a prevailing northward component of the winds through Bering Strait. Consistent with Fig. 9, the regression maps of Fig. 10 confirm that the atmospheric forcing associated with mode 1 is much greater during the wintertime, and that the SLP and wind anomaly fields have a weak relationship with GRACE mode 1 during the summer.

The SLP pattern for EOF1 (Fig. 10) is a broad time scale phenomenon spatially similar to the submonthly wintertime variation described by Peralta-Ferriz et al. (2011, their Fig. 3). It is also similar to the basin-coherent mode of variability in Arctic OBP identified by Hughes and Stepanov (2004) for subannual time scales (i.e., their monthly data were high-pass filtered with a cutoff of 9 months). The atmospheric pattern most highly correlated with the Arctic OBP variations of Hughes and Stepanov (2004) also reveals a high SLP in Scandinavia. Thus, we may argue that the main forcing mechanism that increases the basin-coherent Arctic mass is due to the northward component of the wind that results from the high SLP anomaly near Scandinavia (and to a weaker extent Alaska), and a resultant slope current mainly 


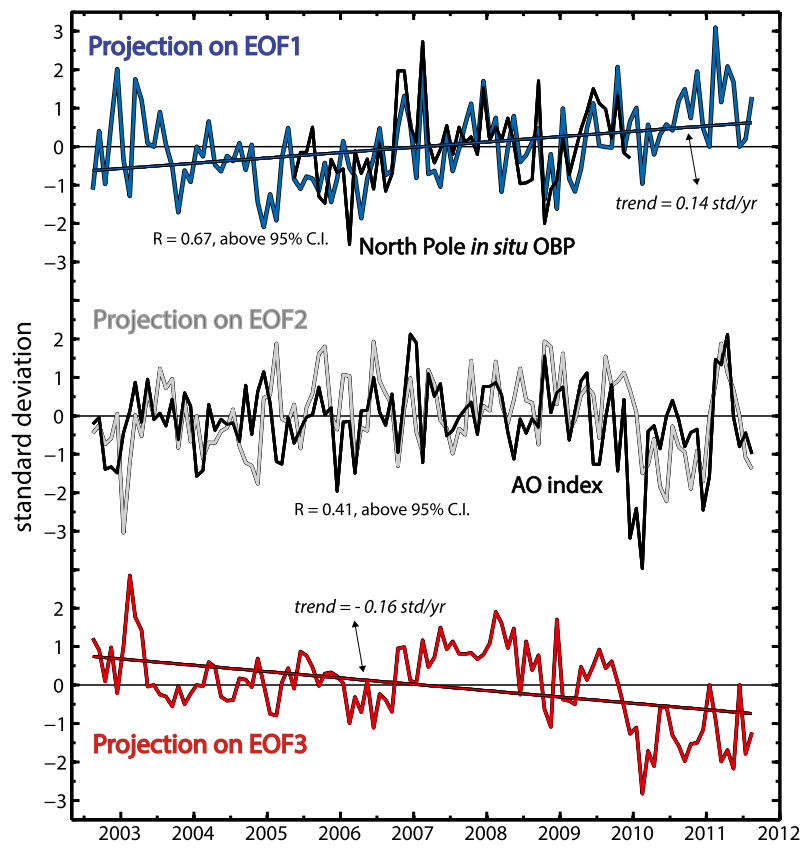

FIG. 8. Projection time series P1, P2, and P3 of the leading EOF modes of GRACE-300 OBP with the mean seasonal variation removed. Units are standard deviations (std). The linear trends of P1 and $\mathrm{P} 3$ are included. $\mathrm{P} 2$ does not show a significant trend. The in situ OBP from the North Pole (less the mean seasonal variation) is superimposed over $\mathrm{P} 1$ (black line). The monthly AO index (black line) is superimposed over $\mathrm{P} 2$.

through Fram Strait. Although the Sverdrup relationship weakens at high latitudes, the SLP pattern could, to a limited extent, also enhance northward transport associated with the strong positive atmospheric vorticity produced by the low SLP centered in the North Atlantic at about $50^{\circ} \mathrm{N}$ (Morison 1991).

The OBP and SSH from the ECCO2 and PIOMAS models are used to investigate the ocean processes in the Arctic Basin associated with EOF1. To do this, the modeled nonseasonal OBP and SSH fields were projected on the time series P1. Since the modeling output ends in December 2009, the regression maps of modeled OBP and SSH, and the corresponding wind field, are projected on P1 from August 2002 to December 2009 only. However, these regression maps are in good agreement with the regression maps that span through August 2011 of Fig. 10. The regression maps of PIOMAS- and ECCO2-derived OBP and SSH are shown in Fig. 11. The contributions of the wintertime change in OBP and SSH to the total OBP change are in agreement with the enhanced winter forcing of this mode. The modeled OBP and SSH changes associated with P1 (Fig. 11) slightly underestimate the amplitude of the OBP variations observed by GRACE EOF1 (Fig. 7, upper left). However, the regression maps of the modeled fields show a spatial pattern consistent with the observed OBP variation from GRACE EOF1.

For most of the deep Arctic Ocean during the winter (Fig. 11, left), the modeled SSH increase is slightly compensated through baroclinic adjustment in the Canada Basin according to PIOMAS and also in other deep basins according to ECCO2. This may suggest that this mode of OBP, mostly of barotropic character, has a small baroclinic contribution in the basin (deep regions).

During the summer months, the winds (Fig. 11, arrows on the right panel) are weakly associated with $\mathrm{P} 1$, in

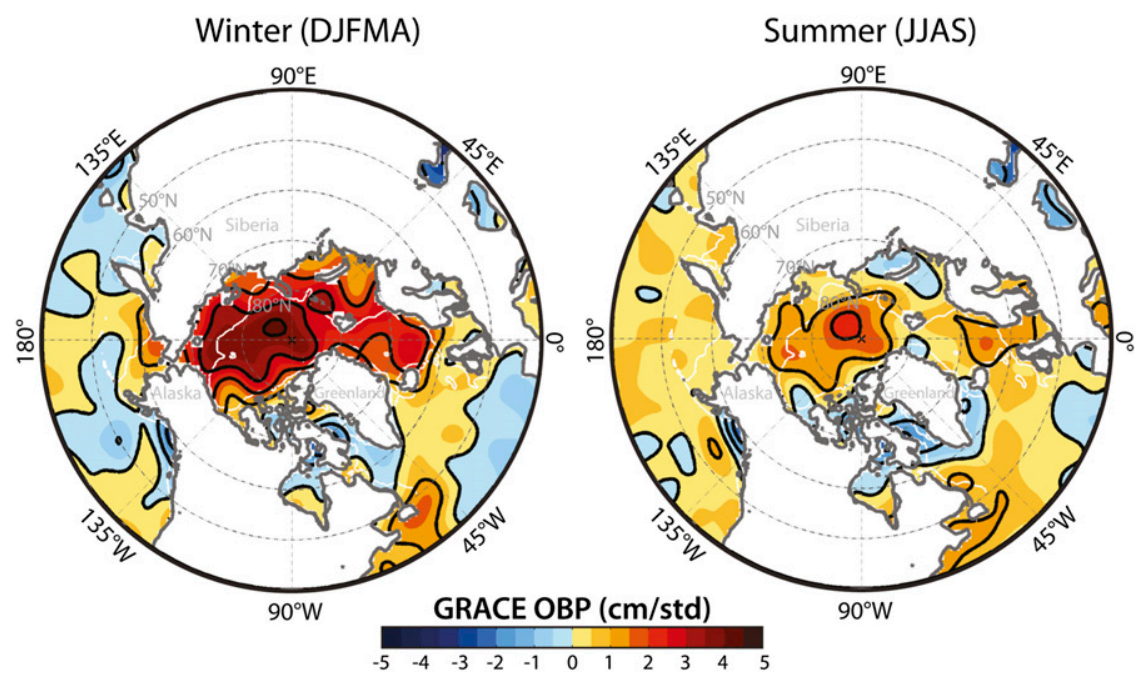

FIG. 9. Regression maps of GRACE OBP projected on time series P1 ( $\left.\mathrm{cm} \mathrm{std}^{-1}\right)$ during (left) winter months (DJFMA) and (right) summer months (JJAS) White line denotes the 500-m isobath from IBCAO data (Jakobsson et al. 2008). Black contour lines are the OBP in $1 \mathrm{~cm} \mathrm{std}^{-1}$ intervals. 


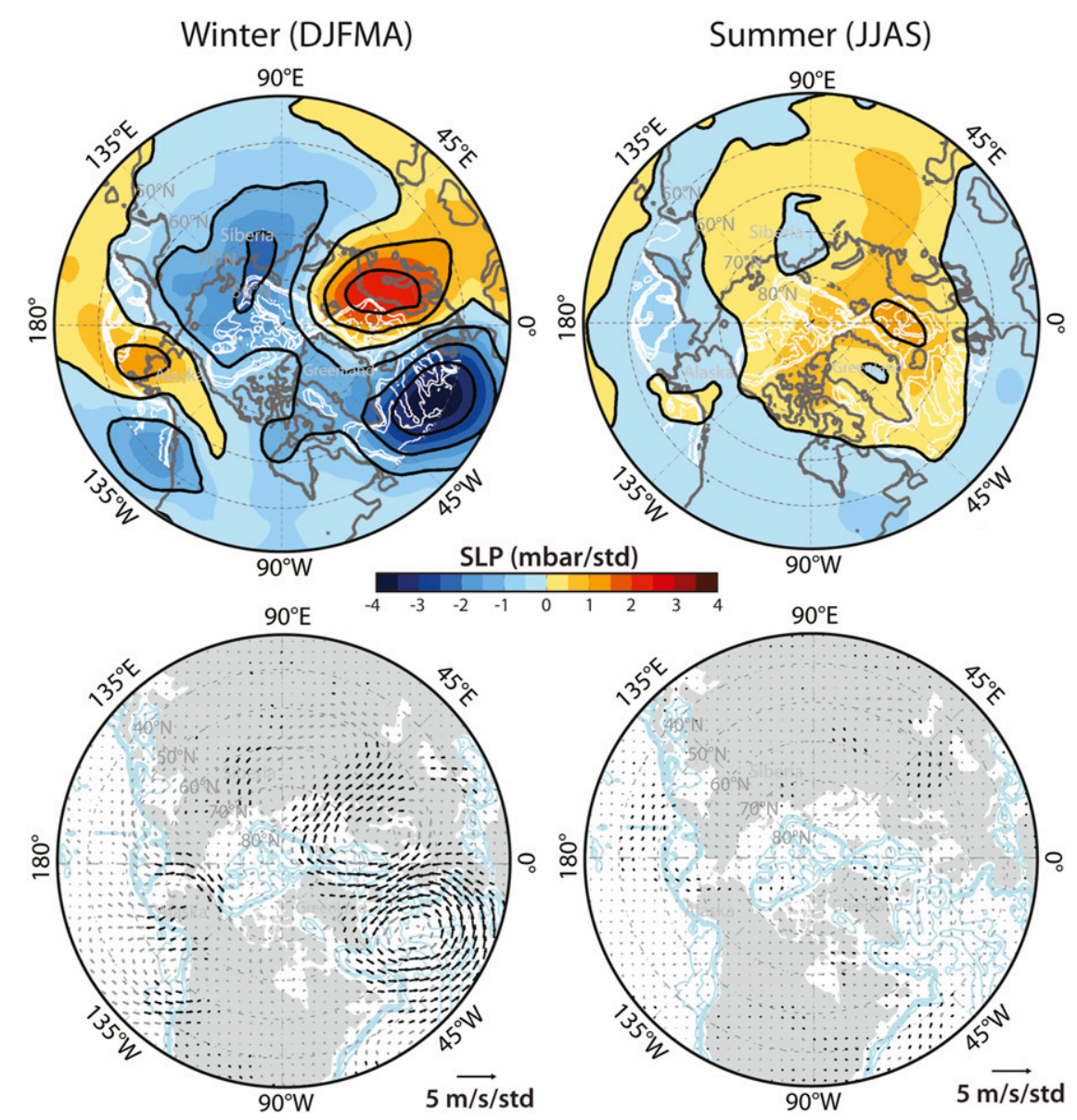

FIG. 10. (top) Regression maps of NCEP-NCAR SLP projected on P1 during (left) winter months (DJFMA) and (right) summer months (JJAS). Units are in millibars per standard deviation $\left(\mathrm{mbar} \mathrm{std}^{-1} ; 1 \mathrm{mbar}=1 \mathrm{hPa}\right)$. (bottom) As at (top), but for the NCEP-NCAR 925-hPa winds. Units are in meters per second per standard deviation $\left(\mathrm{m} \mathrm{s}^{-1} \mathrm{std}^{-1}\right)$. Gray arrows show all wind patterns and black arrows are significant above $95 \%$ CI. Light blue and white contours are the IBCAO data at 1000-m isobath intervals (Jakobsson et al. 2008). Black contour lines are the SLP in $1 \mathrm{mbar}^{-1} \mathrm{std}^{-1}$ intervals.

agreement with the low summertime mass change detected by the observations (Fig. 9, right). Westerly winds and SSH set up along the East Siberian coast in summer are consistent with cyclonic circulation along the Siberian shelves. This pattern of the atmospheric circulation may explain why during the summers, the model OBP and SSH tend to pile water up into the East Siberian and Chukchi Seas.

Overall, GRACE mode 1 is a winter-dominated basin-coherent mode of mass variability in the Arctic Ocean. It is forced by high pressure over Scandinavia and the Nordic seas, and the associated northward winds force a geostrophic slope current through Fram Strait. To a lesser extent, a similar process occurs through Bering Strait, originated by high SLP in Alaska and low SLP over Russia. The models are in agreement with GRACE, and are also consistent with each other in the basin-scale OBP increase.

\section{b. Mode 2: Mass change on the Siberian shelves}

The second mode of OBP variability consists of increasing mass along the Siberian shelves and decreasing mass in the central Arctic (Fig. 7, bottom left). Similar to mode 1 , the atmospheric forcing associated with the mode 2 is investigated by projecting the SLP and wind anomaly fields on the time series P2 (Fig. 12). The resulting regression maps of SLP resemble the spatial pattern of the Arctic expression of the AO (Morison et al. 2012, their Fig. S2b). The AO index is significantly correlated with the time series P2 of GRACE OBP (Fig. 8). The time series $\mathrm{P} 2$ does not reveal any trend, consistent with the AO index from 2003 to 2012, but it 


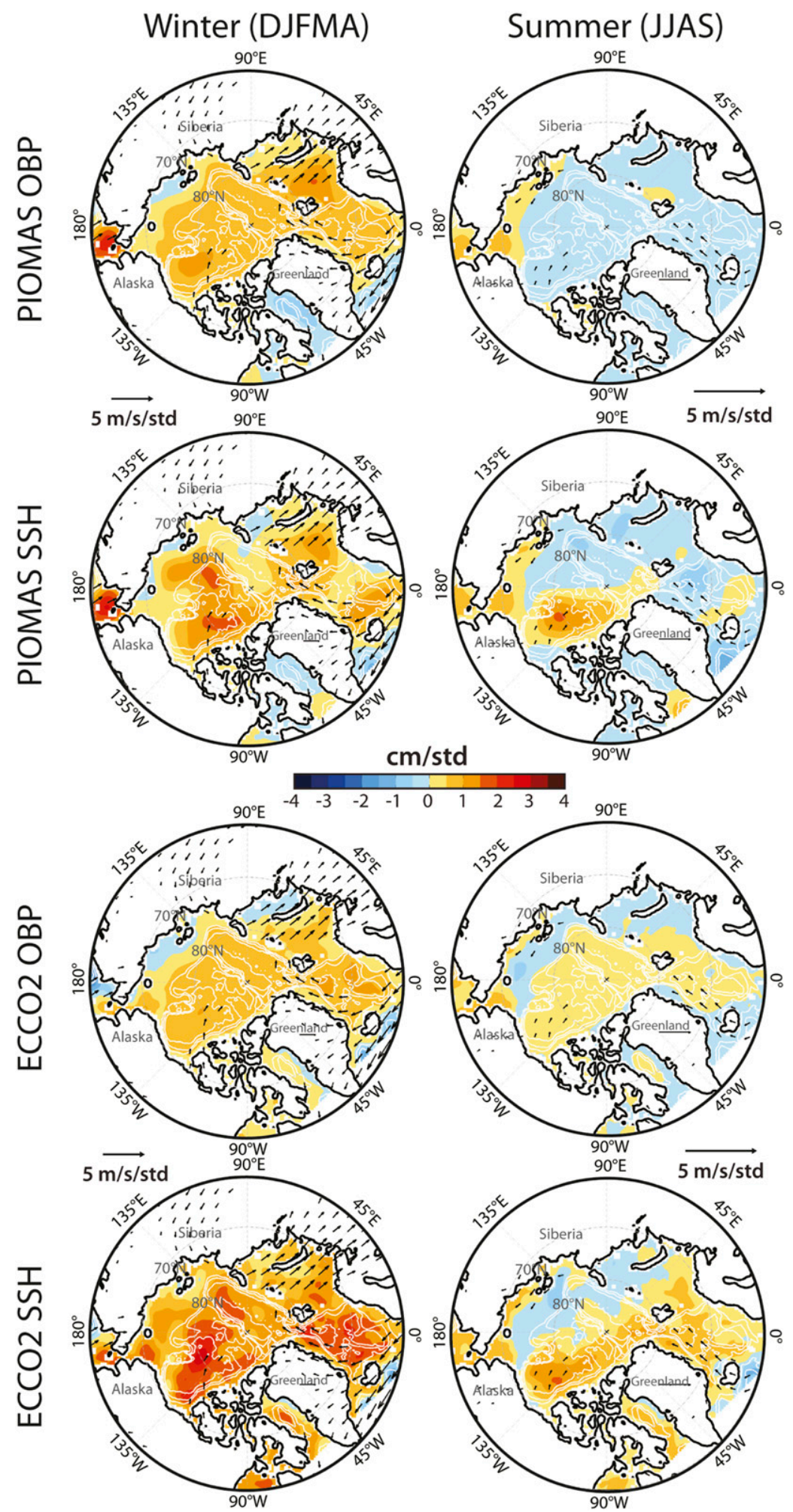

FIG. 11. (top four panels) PIOMAS- and (bottom four panels) ECCO2-modeled OBP and SSH $\left(\mathrm{cm} \mathrm{std}^{-1}\right)$ and NCEP-NCAR winds $\left(\mathrm{m} \mathrm{s}^{-1} \mathrm{std}^{-1}\right)$ projected on P1 during the (left) cold and (right) warm months, from August 2002 to December 2009. Black arrows highlight the wind patterns that are significant above the $95 \%$ of confidence level. White line contours show the IBCAO data at 1000-m intervals (Jakobsson et al. 2008). 


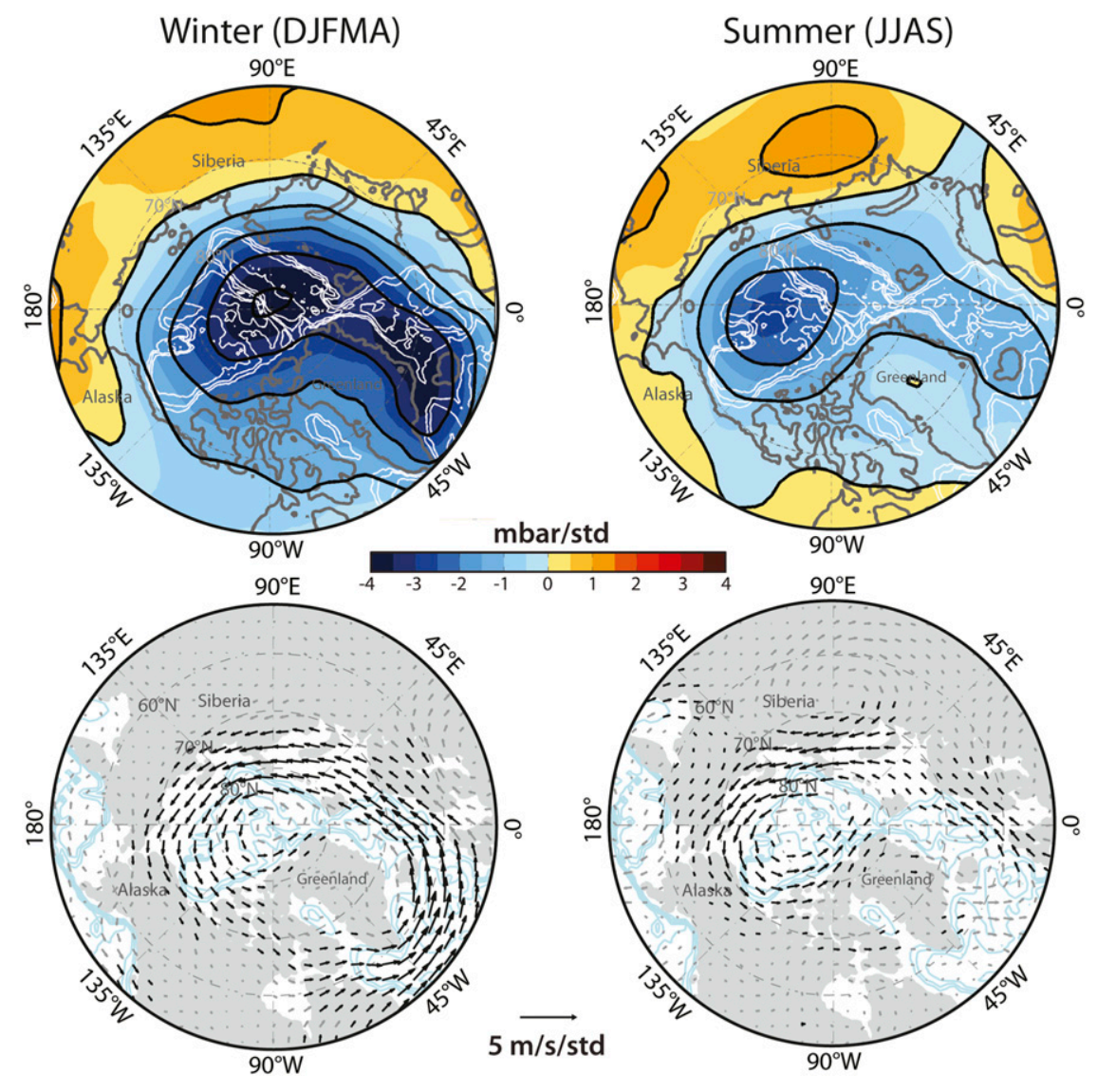

FIG. 12. As in Fig. 10, but projected on P2.

shows a substantial drop at the time of the 2010 record minimum winter AO.

The positive phase of the AO enhances a general cyclonic atmospheric circulation, which tends to offset the Beaufort high, and advance more saline Atlantic Water farther into the Arctic Ocean (Morison et al. 2000, 2012). The regression map of the wind field projected on P2 suggests that the mass change in the Siberian shelves of GRACE mode 2 is due to shoreward Ekman transport; the alongshore cyclonic winds along the Siberian shelves pile the water up to the right from the Barents Sea to the Chukchi Sea, which in turn forces an eastward along-coast flow similar to that which modifies the trajectory of Eurasian runoff at multiyear time scales (Morison et al. 2012).

Figure 12 shows that the atmospheric circulation associated with $\mathrm{P} 2$ is similar throughout the year, but stronger during the winter. Over the Chukchi and East Siberian Seas, the SLP and wind patterns are nearly identical during the summer and the winter. However, during the summer months, the SLP and wind patterns are weaker than the winter patterns everywhere else.
The regression maps between modeled OBP and SSH, projected on P2 (Fig. 13), reveal an increase in OBP that is equivalent to the increase in $\mathrm{SSH}$, along all the Siberian shelves from the Barents to the Chukchi Sea. Both modeled patterns resemble the observed pattern of the EOF2 in Fig. 7 (bottom left). Note that this GRACEmodel agreement occurs regardless of the low correlation obtained between GRACE and in situ data in the Kara and Barents Seas (Table 2, stations 5-8) and between GRACE and each of the models (Fig. 6), which indicates that even if the GRACE solutions of OBP in the Kara and Barents Seas are contaminated with mass signal leakage from land, GRACE is observing real signals of ocean mass change there. This is also consistent with the findings of Volkov et al. (2013) that showed substantial mass-dominated sea level variability in the Barents Sea at nonseasonal time scales.

The modeled SSH and OBP change in the Barents and Kara Seas is weaker during the summer, compared to the SSH and OBP change in the same region during the winter, in agreement with the atmospheric forcing. The ocean response from ECCO2 during the summer months (Fig. 13) suggests that the SSH and OBP 


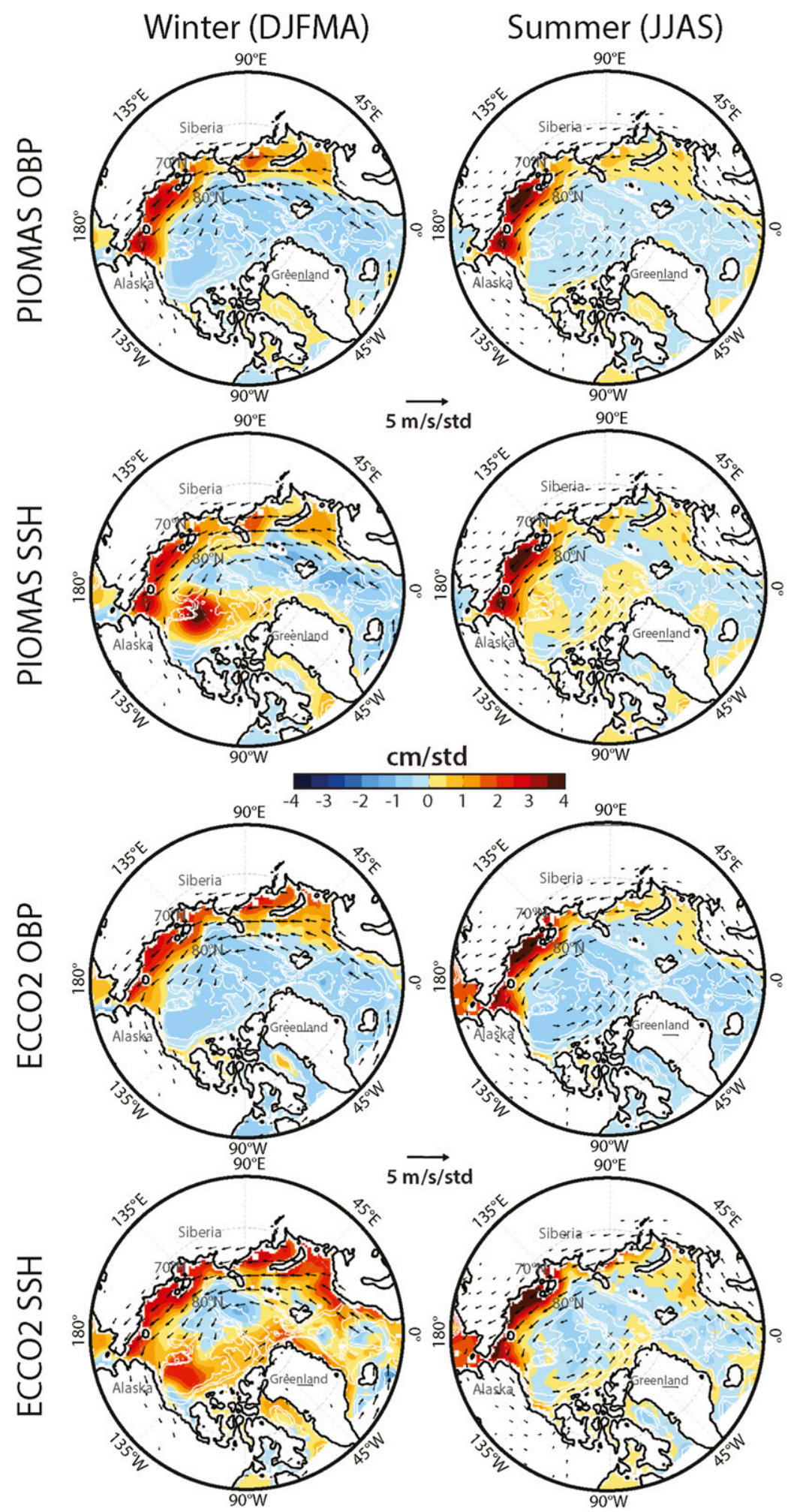

FIG. 13. As in Fig. 11, but projected on P2. 


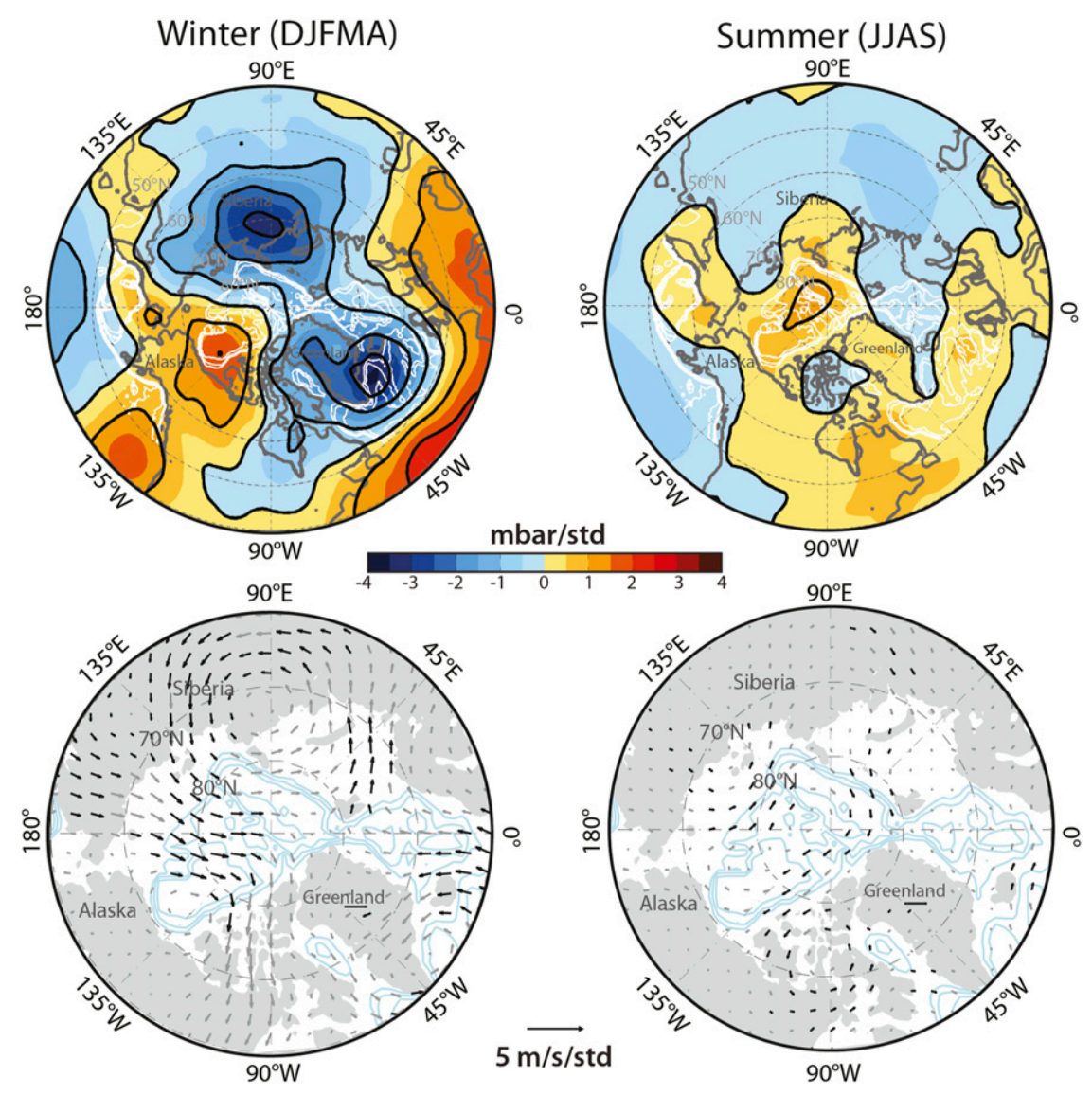

FIG. 14. As in Fig. 10, but projected on P3.

changes in the Chukchi and East Siberian Seas are slightly larger in the summer than in the winter regardless of the similar strength of the winds there between the seasons. We speculate that the lack of sea ice during the summer allows a stronger summer response to the atmospheric forcing there.

For P2, the change in OBP on the shelves is of the same amplitude as the change in SSH for the respective models, regardless of the season (Fig. 13). This correspondence suggests that the ocean response associated with EOF2 is essentially of barotropic character on shallow water (not true for deep basins).

Overall, GRACE mode 2 consists of a mass increase along the Siberian shelves forced by cyclonic winds that are strongly associated with the AO. The mass change is the result of surface Ekman transport that increases the ocean mass on the shelves.

\section{c. Mode 3: Mass change dipole within the Eurasian Arctic shelves}

The EOF mode 3 (Fig. 7, bottom right) reveals a dipole of mass change with one center of action in the Beaufort, Chukchi, and East Siberian Seas and the other center of action in the Kara and Barents Seas. This mode explains $9 \%$ of the total variance of the GRACE field. In contrast to P1 and P2, P3 contains a distinct lowfrequency variation (Fig. 8).

In contrast to the spatial patterns of SLP and wind field associated with EOF1 and EOF2, the shapes of the spatial patterns associated with EOF3 are very different during the summer versus during the winter (Fig. 14). The dipole in the spatial pattern of GRACE EOF3 may be attributed to the atmospheric circulation in wintertime, characterized by a low in SLP centered over the Laptev and Kara Seas, associated with a large cyclonic pattern, and a high in SLP associated with a smaller anticyclonic pattern over the southern Beaufort Sea (Fig. 14, bottom left). However, during the summer months, the SLP dipole disappears, and the atmospheric pattern associated with $\mathrm{P} 3$ is characterized by an anticyclonic circulation that encompasses essentially all the Arctic Ocean (Fig. 14, upper right). The recent tendency toward anticyclonic winds over the Arctic Ocean during summertime has been reported by Ogi and Wallace (2012). Thus, this mode is likely capturing the interannual variability of OBP due in part to anticyclonic wind forcing in the summer. 
We look at the modeled OBP and SSH associated with $\mathrm{P} 3$ to investigate the ocean dynamics that produce the EOF3 pattern. The relationship between the modeled fields of OBP and SSH with P3 (Fig. 15) is, like the atmospheric pattern, different during winter months and summer months. A common pattern among the seasons is the prevailing drop of mass in the Chukchi, East Siberian, and Laptev Seas in both summer and wintertime. During the summer, anticyclonic winds tend to converge mass in the central Arctic via Ekman transport, resulting in a decrease of OBP and SSH along the coast of the Chukchi, East Siberian, and Laptev Seas. The modeled summer decrease in OBP is of the same magnitude as the decrease in SSH (Fig. 15). This result also confirms the modeling results of Bingham and Hughes (2008) that for shallow depths (e.g., the Chukchi, East Siberian, and Laptev Seas) the ocean tends to be more barotropic, even at interannual time scales.

What process produces the decrease in OBP and SSH in the Chukchi, East Siberian, and Laptev Seas during the wintertime (Fig. 15, left)? We speculate that the main forcing of the winter mode EOF3 is a combination of two processes. At the largest spatial scale, the low SLP centered in the eastern Arctic enhances strong divergence of mass away from the Laptev Sea region and into the Canada Basin and the Barents Sea. At a smaller scale, the strengthening of the Beaufort high converges mass into the Canada Basin while removing mass from the coastal regions where the drop of mass is observed and modeled. Also, the mass on the East Siberian Sea might sometimes respond directly to the offshore winds because these shelves are very shallow ( $\sim 20 \mathrm{~m}$ deep). The winter OBP decrease on the shelves is of the same amplitude as the SSH decrease, suggesting that this winter process is of barotropic character on the shelves. However, in the deeper basin, the SSH increase is slightly larger than the OBP decrease, suggesting that the SSH change may be slightly compensated baroclinically in the deep basins.

Overall, the wintertime build-up of SSH in the Canada Basin is positioned so as to suggest it is as a result of the large-scale cyclonic circulation centered roughly over the Kara and Laptev Seas, rather than the smaller anticyclonic circulation centered over the southern Beaufort Sea. The mass buildup in the Barents and Kara Seas (Fig. 7, bottom right) is also part of this divergent pattern resulting from cyclonic atmospheric forcing. During the winter, southwesterly winds from the Nordic seas tend to blow into the Barents Sea, producing a slight increase in both modeled OBP and SSH in Barents and Kara Seas (Fig. 15, left). Thus, the observed OBP increase of GRACE EOF3 over the Kara and Barents Seas (Fig. 7, bottom right) is a wintertime process, and is of barotropic character.
$\mathrm{P} 3$ is on average low ( $-1 \mathrm{std})$ from mid-2003 to mid2006 (Fig. 8), and becomes on average around 1 std high from late 2006 to late 2009 . P3 changes polarity again from the beginning of 2010 until the end of the record in August 2011. This later period is not captured by the models, because the model output used here only includes results through 2009 .

Figure 8, along with Fig. 15, suggests that during times of positive P3 (2007-09), the Beaufort high strengthens because of prevailing anticyclonic winds over the Beaufort Sea for all months, consistent with modeled SSH increase in the Canada and Makarov Basins. The superimposed declining trend of $\mathrm{P} 3$, however, could possibly suppress the effects of the strengthening of the Beaufort high on the mass distribution at longer time scales.

\section{Summary and conclusions}

In this paper, changes and distribution in the Arctic Ocean bottom pressure field were used for the first time to identify different ocean circulation patterns and their associated atmospheric forcing. These patterns were identified using EOF analysis on nine years of monthly GRACE data, from 2002 to 2011, with the mean seasonal variation removed. Together, the three leading modes of variability explain nearly $80 \%$ of the GRACEOBP total variance.

The first mode ( $\sim 50 \%$ of the variance) corresponds to a basin-coherent change in OBP that is also observed in the monthly averages of in situ pressure record at the North Pole. Forced by northward winds over the Nordic seas and to a lesser extent over Bering Strait, this mode is energetic during the winter and weak during the summer. The basin-coherent mass increase appears to respond to inflow mainly through Fram Strait via a northward slope current: the northward component of the wind sets up a surface slope to the east, which in turn enhances a northward geostrophic flow into the Arctic Ocean.

The second mode ( $\sim 20 \%$ of the variance) involves an OBP increase in the Siberian shelves, and an OBP decrease in the central Arctic. This mode is attributed to the AO. In several other studies, many changes in the Arctic have been related or attributed to the strength of the (mainly wintertime) AO (Rigor and Wallace 2004). Here, the AO's effects on the mass distribution in the basin have been isolated for the first time on a monthly basis within nearly a decade of observations of OBP from GRACE with full coverage of the Arctic Ocean. A positive AO pattern is characterized by anomalously low SLP, and is associated with strong cyclonic winds along the Siberian shelves that 


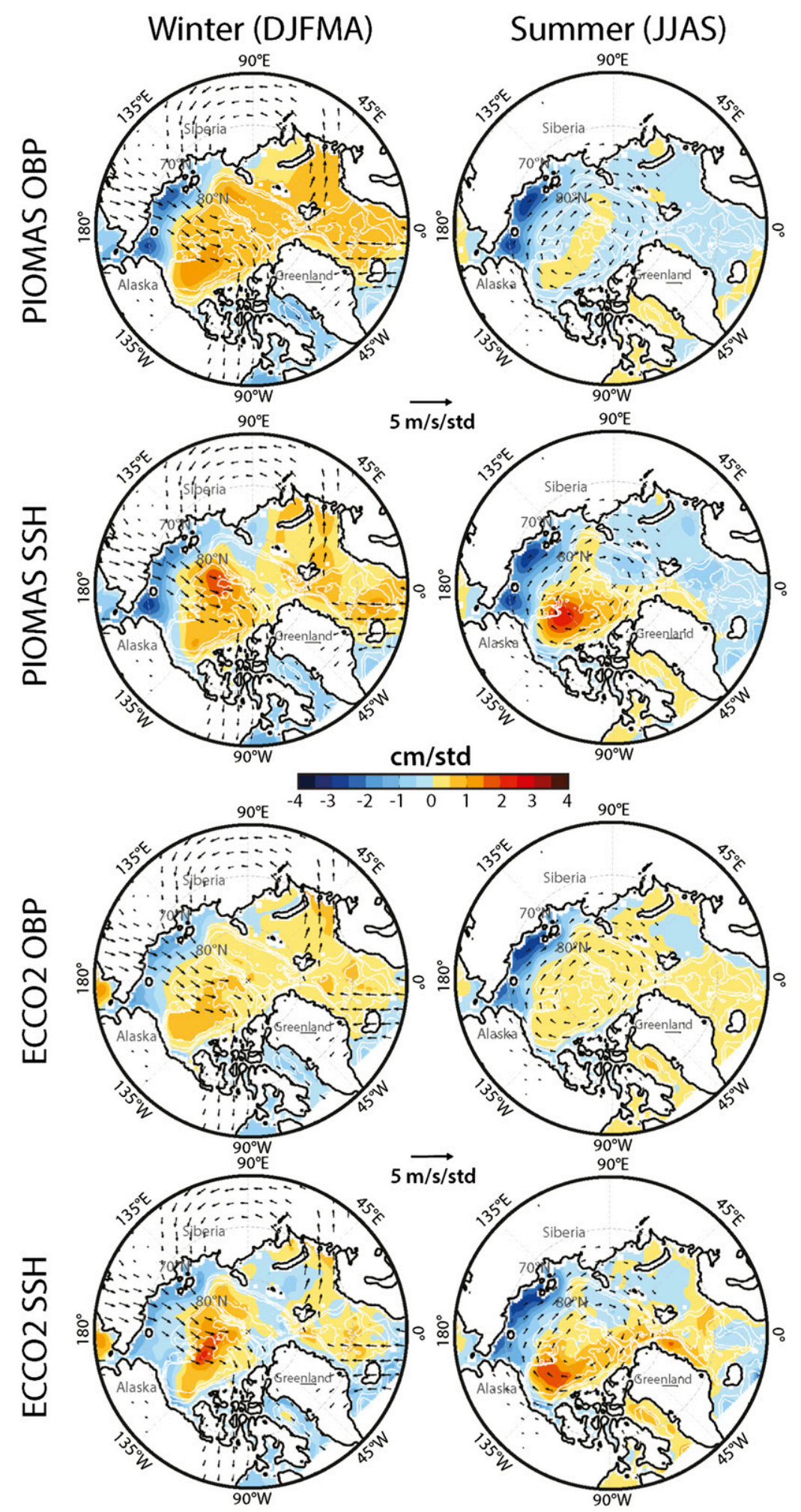

FIG. 15. As in Fig. 11, but projected on P3. 
increase the mass toward the coast. The ocean models used here are in agreement with such dynamics, and are consistent with GRACE. The SSH change from the models is fully captured by the OBP change, suggesting that the ocean response to $\mathrm{AO}$ in the shelves is of barotropic character. A secondary flow alongshore and eastward, via slope current, may emerge out of the mass pile-up onto the Siberian shelves. This slope current would be an effective way to direct riverine water eastward along the shelve break and into the Canada Basin (Morison et al. 2012).

The third mode ( $\sim 10 \%$ of the variance) is characterized by a dipole of mass change with opposing centers of action in the Beaufort, Chukchi, and East Siberian Seas versus the Barents and Kara Seas. The characteristics and forcing of this mode are different during the summer and during the winter. During the summer, basin-scale anticyclonic winds remove the mass from the Siberian shelves via surface Ekman transport. During the winter, this mode appears to be forced by the combination of two different patterns: a strong cyclonic atmospheric circulation centered on the Laptev Sea that diverges mass into the Canada Basin, and the strengthening of the anticyclonic Beaufort high. Also, during the winter, alongshore westerly winds over the Barents Seas, associated with the large-scale low in SLP over the Laptev Sea, increase the OBP in the Barents and Kara Seas via surface Ekman transport. The barotropic character on the shelves and baroclinic character on the deep basins that correspond to this mode are consistent with the modeling results of Bingham and Hughes (2008).

This work is in a sense an observational perspective of the work of Vinogradova et al. (2007) and Bingham and Hughes (2008). Based on the results from this paper, at the time scales and the places where the Arctic Ocean is barotropic (i.e., predominantly on the shelves), GRACE OBP may be used to identify SSH variations. Analogously, satellite altimetry with a polar orbit (e.g., Cryosat-2, or formerly ICESat) may be used to identify changes in the circulation that is dominated by barotropic motion. In those locations where the ocean circulation is predominantly barotropic through all time scales (i.e., the Chukchi, East Siberian, and Laptev Seas), a longer record of GRACE would be fundamental to study the trend in SSH as reported by Proshutinsky et al. (2009) using available tide gauges. The sparseness of the tide gauge data in space and time has made this trend difficult to investigate in the past.

Finally, it is important to recognize that the changes in the Arctic Ocean circulation at shorter (e.g., submonthly) time scales may affect the intensity of the variations in the circulation at longer time scales, and vice versa. The atmospheric forcing of the GRACE mode 1 is very similar to the forcing at submonthly time scales described in Peralta-Ferriz et al. (2011), and to the forcing at intraseasonal time scales described in Hughes and Stepanov (2004). The interplay between the processes occurring at different time scales, along with its consequences on the ocean properties, deserves to be investigated further.

Acknowledgments. The authors wish to thank An Nguyen and Ron Kwok for sharing the output of the ECCO2 model and for fundamental discussions and explanations about the model. This work has been supported by NASA Grants NNX08AH626 and NNX12AK74G, and NSF Grant ARC-0856330. The authors sincerely thank the editor and two anonymous reviewers for their insightful comments and suggestions, which greatly improved this manuscript.

\section{REFERENCES}

Aagaard, K., and E. Carmack, 1989: The role of sea ice and other fresh water in the Arctic circulation. J. Geophys. Res., 94, 14485-14498.

Bingham, R. J., and C. W. Hughes, 2008: The relationship between sea-level and bottom pressure variability in an eddy permitting ocean model. Geophys. Res. Lett., 35, L03602, doi:10.1029/ 2007 GL032662.

Bonin, J. A., and D. P. Chambers, 2013: Uncertainty estimates of a GRACE inversion modelling technique over Greenland using a simulation. Geophys. J. Int., 194, 212-229, doi:10.1093/ gji/ggt091.

Chambers, D. P., 2006a: Observing seasonal steric sea level variations with GRACE and satellite altimetry. J. Geophys. Res., 111, C03010, doi:10.1029/2005JC002914.

_ 2006b: Evaluation of new GRACE time-variable gravity data over the ocean. Geophys. Res. Lett., 33, L17603, doi:10.1029/ 2006 GL027296.

_ , and J. K. Willis, 2009: Low-frequency exchange of mass between ocean basins. J. Geophys. Res., 114, C11008, doi:10.1029/2009JC005518.

Comiso, J. C., 2012: Large decadal decline of the Arctic multiyear ice cover. J. Climate, 25, 1176-1193.

Giles, K. A., S. W. Laxon, A. L. Ridout, D. J. Wingham, and S. Bacon, 2012: Western Arctic Ocean freshwater storage increases by wind-driven spin-up of the Beaufort Gyre. Nat. Geosci., 5, 194-197, doi:10.1038/ngeo1379.

Gill, A. E., and P. Niiler, 1973: The theory of seasonal variability in the ocean. Deep-Sea Res., 20, 141-177.

Hibler, W. D., and K. Bryan, 1987: A diagnostic ice-ocean model. J. Phys. Oceanogr., 7, 987-1015.

$\mathrm{Hu}$, A., and Coauthors, 2010: Influence of Bering Strait flow and North Atlantic circulation on glacial sea-level changes. Nat. Geosci., 3, 118-121.

Hughes, C. W., and V. N. Stepanov, 2004: Ocean dynamics associated with rapid $\mathrm{J} 2$ fluctuations: Importance of circumpolar modes and identification of a coherent Arctic mode. J. Geophys. Res., 109, C06002, doi:10.1029/ 2003JC002176. 
Hunke, E. C., M. Maltrud, and M. Hecht, 2008: On the grid dependence of lateral mixing parameterizations for global ocean simulations. Ocean Modell., 20, 115-133, doi:10.1016/ j.ocemod.2007.06.010.

Jakobsson, M., R. Macnab, L. Mayer, R. Anderson, M. Edwards, K. Hatzly, H.-W. Schenke, and P. Johnson, 2008: An improved bathymetric portrayal of the Arctic Ocean: Implications for ocean modeling and geological, geophysical and oceanographic analyses. Geophys. Res. Lett., 35, L07602, doi:10.1029/ 2008GL033520.

Kalnay, E., and Coauthors, 1996: The NCEP/NCAR 40-Year Reanalysis Project. Bull. Amer. Meteor. Soc., 77, 437-471.

Kanzow, T., F. Flechtner, A. Chave, R. Schmidt, P. Schwintzer, and U. Send, 2005: Seasonal variation of ocean bottom pressure from Gravity Recovery and Climate Experiment (GRACE): Local validation and global patterns. J. Geophys. Res., 110, C09001, doi:10.1029/2004JC002772.

Kwok, R., and D. A. Rothrock, 2009: Decline in Arctic sea ice thickness from submarine and ICESat records: 1958-2008. Geophys. Res. Lett., 36, L15501, doi:10.1029/2009GL039035.

—_, and J. Morison, 2011: Dynamic topography of the ice-covered Arctic Ocean from ICESat. Geophys. Res. Lett., 38, L02501, doi:10.1029/2010GL046063.

Lammers, R. B., A. I. Shiklomanov, C. J. Vorosmarty, B. Fekete, and B. J. Peterson, 2001: Assessment of contemporary Arctic river runoff based on observational discharge records. J. Geophys. Res., 106 (D4), 3321-3334.

Landerer, F. W., and S. C. Swenson, 2012: Accuracy of scaled GRACE terrestrial water storage estimates. Water Resour. Res., 48, W04531, doi:10.1029/2011WR011453.

Luther, D., and A. Chave, 1993: Observing integrating variables in the ocean. Proc. Seventh 'Aha Huliko'a Hawaiian Winter Workshop on Statistical Methods in Physical Oceanography, Honolulu, HI, SOEST, 103-128.

McPhee, M. G., A. Proshutinsky, J. H. Morison, M. Steele, and M. B. Alkire, 2009: Rapid change in freshwater content of the Arctic Ocean. Geophys. Res. Lett., 36, L10602, doi:10.1029/ 2009GL037525.

Morison, J., 1991: Seasonal variations in the West Spitsbergen Current estimated from bottom pressure measurements. J. Geophys. Res., 96 (C10), 18381-18395.

_, K. Aagaard, and M. Steele, 2000: Recent environmental changes in the Arctic: A review. Arctic, 53 (4), 359-371.

- M. Steele, T. Kikuchi, K. Falkner, and W. Smethie, 2006: Relaxation of central Arctic Ocean hydrography to pre-1990s climatology. Geophys. Res. Lett., 33, L17604, doi:10.1029/ 2006 GL026826.

_ J. Wahr, R. Kwok, and C. Peralta-Ferriz, 2007: Recent trends in Arctic Ocean mass distribution revealed by GRACE. Geophys. Res. Lett., 34, L07602, doi:10.1029/2006GL029016.

—, R. Kwok, C. Peralta-Ferriz, M. Alkire, I. Rigor, R. Andersen, and M. Steele, 2012: Changing Arctic Ocean freshwater pathways. Nature, 481, 66-70.

Munekane, H., 2007: Ocean mass variations from GRACE and tsunami gauges. J. Mar. Res., 112, B07403, doi:10.1029/ 2006JB004618

Nguyen, A. T., D. Menemenlis, and R. Kwok, 2011: Arctic iceocean simulation with optimized model parameters: Approach and assessment. J. Geophys. Res., 116, C04025, doi:10.1029/2010JC006573.

North, G. R., T. L. Bell, and R. F. Cahalan, 1982: Sampling errors in the estimation of empirical orthogonal functions. Mon. Wea. Rev., 110, 699-706.
Ogi, M., and J. M. Wallace, 2012: The role of summer surface wind anomalies in the summer Arctic sea ice extent in 2010 and 2011. Geophys. Res. Lett., 39, L09704, doi:10.1029/2012GL051330.

Overland, J. E., M. Wang, and S. Salo, 2008: The recent Arctic warm period. Tellus, 60, 589-597, doi:10.1111/j.1600-0870.2008.00327.x.

Paulson, A., S. Zhong, and J. Wahr, 2007: Inference of mantle viscosity from GRACE and relative sea level data. Geophys. J. Int., 171, 497-508, doi:10.1111/j.1365-246X.2007.03556.x.

Peralta-Ferriz, C., and J. Morison, 2010: Understanding the annual cycle of the Arctic Ocean bottom pressure. Geophys. Res. Lett., 37, L10603, doi:10.1029/2010GL042827.

— — - J. M. Wallace, and J. Zhang, 2011: A basin-coherent mode of sub-monthly variability in Arctic Ocean bottom. Geophys. Res. Lett., 38, L14606, doi:10.1029/2011GL048142.

Polyakov, I. V., and Coauthors, 2010: Arctic Ocean warming contributes to reduced polar ice cap. Phys. Oceanogr., 40, 2743-2756.

Ponte, R. M., 1999: A preliminary model study of the large-scale seasonal cycle in bottom pressure over the global ocean. J. Geophys. Res., 104 (C1), 1289-1300.

Proshutinsky, A. R., and Coauthors, 2009: Beaufort Gyre freshwater reservoir: State and variability from observations. J. Geophys. Res., 114, C00A10, doi:10.1029/2008JC005104.

Rabe, B., and Coauthors, 2011: An assessment of Arctic Ocean freshwater content changes from the 1990s to the 2006-2008 period. Deep-Sea Res. I, 58, 173-185.

Rietbroek, R., P. LeGrand, B. Wouters, J.-M. Lemoine, G. Ramillien, and C. W. Hughes, 2006: Comparison of in situ bottom pressure data with GRACE gravimetry in the Crozet-Kerguelen region. Geophys. Res. Lett., 33, L21601, doi:10.1029/2006GL027452.

Rigor, I. G., and J. M. Wallace, 2004: Variations in the age of Arctic sea-ice and summer sea-ice extent. Geophys. Res. Lett., 31, L09401, doi:10.1029/2004GL019492.

— - - and R. L. Colony, 2002: Response of sea ice to the Arctic Oscillation. J. Climate, 15, 2648-2663.

Roussenov, V. M., R. G. Williams, C. W. Hughes, and R. J. Bingham, 2008: Boundary wave communication of bottom pressure and overturning changes for the North Atlantic. J. Geophys. Res., 113, C08042, doi:10.1029/2007JC004501.

Serreze, M. C., and Coauthors, 2006: The large-scale freshwater cycle of the Arctic. J. Geophys. Res., 111, C11010, doi:10.1029/ $2005 \mathrm{JC} 003424$.

Steele, M., and T. Boyd, 1998: Retreat of the cold halocline layer in the Arctic Ocean. J. Geophys. Res., 103 (C5), 10419 10435 .

J. Morison, W. Ermold, I. Rigor, M. Ortmeyer, and K. Shimada, 2004: Circulation of summer Pacific halocline water in the Arctic Ocean. J. Geophys. Res., 109, C02027, doi:10.1029/2003JC002009.

_ - W. Ermold, and J. Zhang, 2008: Arctic Ocean surface warming trends over the past 100 years. Geophys. Res. Lett., 35, L02614, doi:10.1029/2007GL031651.

Stepanov, V. N., and C. W. Hughes, 2006: Propagation of signals in basin-scale ocean bottom pressure from a barotropic model. J. Geophys. Res., 111, C12002, doi:10.1029/2005JC003450.

Stroeve, J., M. M. Holland, W. Meier, T. Scambos, and M. Serreze, 2007: Arctic sea ice decline: Faster than forecast. Geophys. Res. Lett., 34, L09501, doi:10.1029/2007GL029703.

—, A. Frei, J. McCreight, and D. Ghatak, 2008: Arctic sea-ice variability revisited. Ann. Glaciol., 48, 71-81.

Swenson, S. C., and J. Wahr, 2006: Post-processing removal of correlated errors in GRACE data. Geophys. Res. Lett., 33, L08402, doi:10.1029/2005GL025285. 
Thompson, D. W., and J. M. Wallace, 1998: The Arctic Oscillation signature in the wintertime geopotential height and temperature fields. Geophys. Res. Lett., 25, 1297-1300.

Vinogradova, N. T., R. M. Ponte, and D. Stammer, 2007: Relation between sea level and bottom pressure and the vertical dependence of oceanic variability. Geophys. Res. Lett., 34, L03608, doi:10.1029/2006GL028588.

Volkov, D. L., F. W. Landerer, and S. A. Kirillov, 2013: The genesis of sea level variability in the Barents Sea. Cont. Shelf Res., 66, 92-104, doi:10.1016/j.csr.2013.07.007.
Wahr, J. M., M. Molenaar, and F. O. Bryan, 1998: Time variability of the Earth's gravity field: Hydrological and oceanic effect and their possible detection using GRACE. J. Geophys. Res., 103, 30205-30229.

Wearn, R. B., and D. J. Baker, 1980: Bottom pressure measurements across the Antarctic Circumpolar Current and their relation to wind. Deep-Sea Res., 27, 875-888.

Zhang, J., and D. A. Rothrock, 2003: Modeling global sea ice with a thickness and enthalpy distribution model in generalized curvilinear coordinates. Mon. Wea. Rev., 131, 845-861. 